\title{
miR156/SPL9 Regulates Reactive Oxygen Species Accumulation and Immune Response in Arabidopsis thaliana
}

\author{
Hongbiao Yin,1,2 Gaojie Hong,,2 Linying Li,2,3 Xueying Zhang,2,4 Yaze Kong,,2,5 Zongtao Sun,2,6 \\ Junmin Li,2,6 Jianping Chen, 1,2,6 and Yuqing $\mathrm{He}^{2, \dagger}$ \\ ${ }^{1}$ College of Chemistry and Life Science, Zhejiang Normal University, Jinhua 321004, China; ${ }^{2}$ State Key Laboratory Breeding Base for Zhejiang \\ Sustainable Pest and Disease Control, Ministry of Agriculture Key Laboratory of Biotechnology in Plant Protection, Zhejiang Provincial Key \\ Laboratory of Plant Virology, Institute of Virology and Biotechnology, Zhejiang Academy of Agricultural Sciences, 198 Shiqiao Road, \\ Hangzhou 310021, China; ${ }^{3}$ School of Horticulture and Plant Protection, Yangzhou University, Yangzhou 225009, China; ${ }^{4}$ Department of Tea \\ Science, Zhejiang University, Hangzhou 310058, China; and ${ }^{5}$ College of Life Sciences, Zhejiang Sci-Tech University, Hangzhou 310018, \\ China; and ${ }^{6}$ Institute of Plant Virology, Ningbo University, Ningbo 315211, China
}

Accepted for publication 6 December 2018.

\begin{abstract}
The functions of microRNA156 (miR156) and its targeted SQUAMOSA PROMOTER BINDING PROTEIN-LIKE (SPL) transcription factor genes in plant development have been widely investigated. However, the role of the miR156/SPLS regulatory network in plant immune systems remains obscure. Here, we found that the accumulation of reactive oxygen species (ROS) and the transcripts of basal salicylic acid (SA) signaling pathway genes were lower in Arabidopsis Pro35S:MIR156 seedlings (miR156 overexpression mutants) but higher in Pro35S:MIM156 (miR156 repression mutants) and ProSPL9:rSPL9 (SPL9 overexpression mutants) seedlings compared with wild-type Col-0 plants (WT). As a result, Pro35S:MIR156 mutants induced greater susceptibility to Pseudomonas

syringae pv. tomato DC3000 following syringe infiltration than WT, while Pro35S:MIM156 and ProSPL9:rSPL9 mutants showed enhanced resistance. In addition, foliar $\mathrm{H}_{2} \mathrm{O}_{2}$ application resulted in activation of SA-mediated defense response and ablation of miR156-induced susceptibility to $P$. syringae pv. tomato DC3000 infection. Collectively, our results provide new insights into the function of the miR156/SPL network in Arabidopsis immune response by regulating ROS accumulation and activating the SA signaling pathway.

Keywords: Arabidopsis thaliana, immune response, miR156, P. syringae pv. tomato DC3000, reactive oxygen species, SA signaling pathway, SPL9.
\end{abstract}

MicroRNAs (miRNAs) are small, endogenous RNAs that posttranscriptionally repress gene expression by cleaving target mRNAs or repressing their translation (Baulcombe 2004; Nozawa et al. 2012). MicroRNA156 (miR156) is a highly conserved miRNA in plants. It targets and suppresses the expression of the SQUAMOSA PROMOTER BINDING PROTEIN-LIKE (SPL) transcription factor gene family, which plays a pivotal role in the regulation of a variety of biological processes in plants (Axtell and Bowman 2008; Wang 2016; Wang and Wang 2015). Overexpression of miR156 leads to prolonged expression of juvenile phage, delayed flowering (Chuck et al. 2007; Wang et al. 2009; Xie et al. 2006), shortened plastochrons, and overproduction of leaves (Schwarz et al. 2008; Wang and Weigel 2008). miR156 positively regulates branching and leaf angle in maize and rice (Bai et al. 2012; Chuck et al. 2007; Ishii et al. 2013; Jiao et al. 2010), whereas it negatively regulates tuberization in potato and nodulation in Lotus japonicus (Bhogale et al. 2014; Wang et al. 2015). Furthermore, OSSPL14 and OSSPL16 enhance grain yield in rice but LeSPL-CNR (an Arabidopsis AtSPL3 ortholog) reduces tuber yield in tomato (Manning et al. 2006; Miura et al. 2010; Wang et al. 2012). The miR156/SPLs network also functions in the regulation of secondary

†Corresponding author: Y. He; E-mail: yqhe_123@126.com

Funding: This work was funded by the National Natural Science Foundation of China (31800249 and 31500242) and Zhejiang Provincial Natural Science Foundation of China (LY16C020004 and LQ18C140004).

*The $\boldsymbol{e}$-Xtra logo stands for "electronic extra" and indicates that five supplementary figures are published online.

The author(s) declare no conflict of interest.

(c) 2019 The American Phytopathological Society metabolism and abiotic stress responses. miR156-targeted AtSPL9 negatively regulate the biosynthesis of anthocyanins and sesquiterpenes but positively modulates the accumulation of glucosinolates (Gou et al. 2011; Mao et al. 2017; Yu et al. 2015). The miR156/SPL module controls copper homeostasis (Arabidopsis AtSPL7, Physcomitrella patens PpSBP2, and Chlamydomonas reinhardtii CRRI) and responses to drought (Medicago sativa SPL13), heat, and cold stress (Arshad et al. 2017; Stief et al. 2014; Yamasaki et al. 2007, 2009; Yang et al. 2017).

miRNAs are critical in plant innate immunity to fungal, bacterial, viral, and nematode infections (Katiyar-Agarwal and Jin 2010; Li et al. 2012). Pathogenic attack always induces or represses the expression of miRNAs, which regulate the expression of key defense genes (Islam et al. 2018; Navarro and Jones 2006). The expression of miR156 has been reported to be repressed in loblolly pine infected by Cronartium quercuum (Lu et al. 2007). SPL6 (AtSPL6 and NbSPLO) has been found to positively regulate innate immunity in Arabidopsis and Nicotiana benthamiana, whereas the Arabidopsis AtSPL14 induces fungal toxin fumonisin B1 susceptibility and AtSPL9 negatively regulates insect resistance (Mao et al. 2017; Padmanabhan et al. 2013; Stone et al. 2005). These findings imply that miR156 and SPLs might play a role in plant innate immunity, yet our knowledge of the immunity mediated by the miR156/SPL network is incomplete and requires extensive investigation.

Reactive oxygen species (ROS) are continually generated as a consequence of the normal metabolism of aerobic organisms (Gechev et al. 2006). Regulation of the accumulation and release of ROS is important, because high levels of ROS cause cell death and low levels regulate stress responses in plants (Camejo et al. 2016; Miller et al. 2010). ROS plays critical roles as signal molecules during plant-pathogen interactions (Camejo et al. 2016). miRNAs control responses to environmental stresses and viral resistance by 
regulating cellular ROS levels (Lu et al. 2011; Wu et al. 2017). miRNAs also regulate the production and signaling pathways of various hormones, directly or indirectly. In turn, these hormones modulate plant immunity and defense responses to invading pathogens by activating the expression of various defenseresponsive genes (Islam et al. 2018; Navarro and Jones 2006; Vidhyasekaran 2015; Zhang et al. 2011). A recent study reported that AtSPL9 negatively regulates jasmonic acid (JA) response (Mao et al. 2017). Based on these findings, we hypothesized that ROS and hormone pathways play a role in the immunity mediated by miR 156 and its SPL target.

To test our hypothesis, three Arabidopsis transgenic plantsPro35S:MIR156 (miR156 overexpression mutant), Pro35S: MIM156 (miR156 repression mutant), and ProSPL9:rSPL9 (SPL9 [one of the $S P L S$ ] overexpression mutant) (Wang and Weigel 2008) — were used to determine whether the miR156/SPL9 module affects ROS accumulation, the expression of salicylic acid (SA) response genes, and responses to bacterial challenge. The analysis indicated that the miR156/SPL9 module controls innate immunity by regulating ROS accumulation and activating of the SA signaling pathway in Arabidopsis.

\section{MATERIALS AND METHODS}

Plant materials and growth conditions. Three mutantsPro35S:MIR156 (Wang and Weigel 2008), Pro35S:MIM156 (Franco-Zorrilla et al. 2007; Wang and Weigel 2008), and Pro35S: rSPL9 (Wang and Weigel 2008)_-along with wild-type Arabidopsis thaliana ecotype Columbia (Col-0) were used in this study.

Surface-sterilized seed were germinated in $1 / 2$ Murashige and Skoog medium ( $\mathrm{pH}$ 5.7) supplemented with $4 \%$ sucrose, $1 \%$ agar, and $0.05 \%$ morpholineethanesulfonic acid. Plated seedlings were grown in a growth chamber at $22^{\circ} \mathrm{C}$ with short days (photoperiod of $8 \mathrm{~h}$ of light and $16 \mathrm{~h}$ of darkness), $60 \%$ relative humidity, and light intensity of $600 \mathrm{mmol}$ photon $\mathrm{m}^{-2} \mathrm{~s}^{-1}$. The 1-week-old seedings were sown in plastic pots ( 9 seedlings/pot) with commercial nutrient soil. These pots were kept in an incubator under the conditions described above. The 5-week-old plants grown with short days ( $8 \mathrm{~h}$ of light and $16 \mathrm{~h}$ of darkness) were considered juvenile (Supplementary Fig. S1) (Telfer et al. 1997).

Histochemical staining of $\mathrm{O}_{2}^{-}$and hydrogen peroxide. To evaluate the in situ accumulation of $\mathrm{O}_{2}^{-}$and hydrogen peroxide $\left(\mathrm{H}_{2} \mathrm{O}_{2}\right)$, histochemical staining was performed using nitroblue tetrazolium (NBT) and 3,3'-diaminobenzidine (DAB), as previously described (Jabs et al. 1996; Torres et al. 2002), with some modifications. Briefly, 1-week-old seedlings were vacuum infiltrated with $1 \mathrm{mM} \mathrm{NBT}$ (Sigma-Aldrich) in $0.01 \mathrm{M}$ phosphate buffer solution (PBS, $\mathrm{pH} 7.0$ ) or DAB (Sigma-Aldrich) at $1 \mathrm{mg} / \mathrm{ml}$ with sodium citrate $(\mathrm{pH} 3.8)$, then incubated at room temperature in the dark for 2 or $24 \mathrm{~h}$, respectively. Seedlings were washed with $75 \%$ ( vol/vol) ethanol to bleach out chlorophyll for $10 \mathrm{~min}$ at $70^{\circ} \mathrm{C}$. The washed seedlings were mounted in $20 \%$ glycerol and photographed using a stereoscope.
Detection of $\mathrm{H}_{2} \mathrm{O}_{2}$ and NADPH oxidase activity in seedling extracts. $\mathrm{H}_{2} \mathrm{O}_{2}$ content and NADPH oxidase activity in 1-week-old seedling and 5-week-old plant leaves extracts were determined. First, $200 \mathrm{mg}$ of fresh seedlings and total juvenile plant leaves were ground with liquid nitrogen and extracted with $5 \mathrm{ml}$ of ice-cold PBS ( $\mathrm{pH} 7.5$ ) containing $2 \%$ polyvinyl pyrrolidone. After incubation on ice for half an hour, the extractions were centrifuged at $12,500 \times g$ at $4{ }^{\circ} \mathrm{C}$ for $20 \mathrm{~min}$ and supernatants were collected for use. To determine the $\mathrm{H}_{2} \mathrm{O}_{2}$ content, an Amplex Red Hydrogen Peroxide/Peroxidase Assay Kit (Invitrogen) was used according to the manufacturer's protocol. The absorbance was measured at $560 \mathrm{~nm}$ using a microplate reader (SpectraMax M5) and $\mathrm{H}_{2} \mathrm{O}_{2}$ was quantified according to the standard curve prepared with known concentrations of $\mathrm{H}_{2} \mathrm{O}_{2}$. To determine NADPH oxidase activity, an aliquot of the isolated supernatant was added to a reaction mixture (NADPH at $0.1 \mathrm{mmol} / \mathrm{liter}, \mathrm{NBT}$ at $0.1 \mathrm{mmol} / \mathrm{liter}$, sucrose at $250 \mathrm{mmol} /$ liter, and Tris- $\mathrm{HCl}$ at $50 \mathrm{mmol} /$ liter, $\mathrm{pH}$ 7.4) according to methods described by Gestelen (1977). The activity was calculated as the rate of decrease in the absorbance of NADPH at $530 \mathrm{~nm}$ with an absorption extinction coefficient of $6.22 \mathrm{mM}^{-1} \mathrm{~cm}^{-1}$.

Total RNA extraction and quantitative real-time polymerase chain reaction. To analyze changes in mRNA levels, quantitative real-time polymerase chain reaction (RT-qPCR) was performed according to a previous report (He et al. 2017). Total RNA from seedlings and the total juvenile plant leaves were extracted using the TRIzol protocol (Invitrogen) in accordance with the manufacturer's instructions. Total RNA $(1 \mu \mathrm{g})$ was synthesized to first-strand cDNA using a HiScript II Q RT for qPRC (+gDNA viper) kit (vazyme). RT-qPCR was performed on a QuantStudio 6 Flex Real-Time PCR System (Applied Biosystems) using a CHamQ SYBR qPCR Master Mix kit (vazyme), following the supplier's protocol. The RT-qPCR conditions were $95^{\circ} \mathrm{C}$ for $3 \mathrm{~min}$ followed by 40 cycles of $95^{\circ} \mathrm{C}$ for $15 \mathrm{~s}, 60^{\circ} \mathrm{C}$ for $15 \mathrm{~s}$, and $72^{\circ} \mathrm{C}$ for $20 \mathrm{~s}$. The mRNA expression levels were normalized against the expression of housekeeping gene ACTIN2 (AT3G18780), and the fold change was calculated by the comparative cycle threshold method $\left(2^{-\Delta \Delta \mathrm{Ct}}\right.$ method) (Livak and Schmittgen 2001). At least three biological replicate samples were used. Differences were considered significant at $P \leq 0.05$. The primers used in this study are listed in Table 1 .

Antioxidant enzyme extraction and activity assay. The seedling and total juvenile plant leaf extracts for determination of antioxidant enzyme activity were prepared as described above. Superoxide dismutase (SOD) activity was assayed by measuring the photochemical reduction rate of NBT at an absorbance of $560 \mathrm{~nm}$ (Stewart and Bewley 1980). Catalase (CAT) activity was tested by detecting the degradation rate of $\mathrm{H}_{2} \mathrm{O}_{2}$ at an absorbance of $240 \mathrm{~nm}$ (Patra et al. 1978). Glutathione reductase (GR) activity was determined by measuring the dehydrogenation rate of NADPH at an absorbance of $340 \mathrm{~nm}$ (Foyer and Halliwell 1976). Monodehydroascorbate reductase (MDAR) activity was determined by measuring a decrease in absorbance at $340 \mathrm{~nm}$ due to NADH oxidation (Hossain et al. 1984). dehydrosacorbate reductase (DHAR) activities were qualified by the reduction rate of

TABLE 1. Primers used in this article

\begin{tabular}{|c|c|c|c|}
\hline Gene ID & Primer name & Forward primer $\left(5^{\prime}\right.$ to $\left.3^{\prime}\right)$ & Reverse primer $\left(5^{\prime}\right.$ to $\left.3^{\prime}\right)$ \\
\hline AT3G54660 & $G R 2$ & CAAAGACTCCTCTGAGGGAAAG & GGGCTCCAATGCCGTAAATA \\
\hline AT3G09940 & $M D A R 3$ & TCAAGAGGAACACAAGGCTATT & CAAGACCCAATGTCTCAAAG \\
\hline AT1G63940 & MDAR6 & GTTCCAGCTTCTACCAAAGCTA & ТССТТСТСТААСТСТGTAGAGC \\
\hline AT4G35090 & $C A T$ & TGTCATTGTCCGGTTCTCCA & GGTGGTGGGAGAAGAAGTCA \\
\hline AT2G14610 & PRI & TGCTCTTGTTCTTCCCTCGA & CTAACCCACATGTTCACGGC \\
\hline AT3G57260 & $P R 2$ & AGAGATGGTGTCAGATTCC & GTGGTGTCAGTGGCTATA \\
\hline At3G04720 & PR4 & TCATACACAGTGGCTACG & GTTGGTCGGAGAACAGTA \\
\hline AT1G75040 & PR5 & TCTCTTCCTCGTGTTCATC & AAGCACCTGGAGTCAATT \\
\hline AT1G64280 & NPR1 & CCGATGTCAACCATAGGA & CATTCAACCGCCATAGTG \\
\hline AT5G45110 & $N P R 3$ & AAGTTGTTGCCGAGATTC & AATGAAGAACCGTGTAACC \\
\hline AT4G19660 & NPR4 & СТААСТССАССТССАТСАА & TATCCAGAACCTCATAACAAG \\
\hline AT3G18780 & ACTIN2 & TGTTCCAGCCCTCGTTTGTGGG & TGCTGCTTGGTGCAAGTGCTGT \\
\hline
\end{tabular}


dehydroascorbate (DHA) at an absorbance of $265 \mathrm{~nm}$ (Nakano and Asada 1981). Peroxidase (POD) activity was determined by the absorbance of $\mathrm{H}_{2} \mathrm{O}_{2}$ oxidation at $470 \mathrm{~nm}$ (Chance and Maehly 1955). All optical density detections were performed on a SpectraMax M5 microplate reader.

SA measurements. The total leaves of 5-week-old plants were collected, ground into a power in liquid nitrogen, and then used for hormone extraction and analysis as described previously (Fu et al. 2012), with some modifications. The internal standard ${ }^{2} \mathrm{H}_{4}-\mathrm{SA}$ (140 pmol) was added to $200 \mathrm{mg}$ of ground powder. The powder was extracted with $2 \mathrm{ml}$ of methanol and further purified by an Oasis mode anion exchange solid-phase extraction column (Waters). The eluate was analyzed by ultraperformance liquid chromatographyelectrospray ionization tandem mass spectrometry (ACQUITY UPLC H-Class and Xevo TQ-S; Waters). Three biological replicates were used, each of which consisted of at least five pooled plants.

Bacterial growth assay. Using the Pseudomonas syringae pv. tomato DC3000 strain, bacterial challenge was performed as described previously (Whalen et al. 1991). Briefly, overnight cultured bacterial cells were collected, washed, resuspended, and

A Col-0

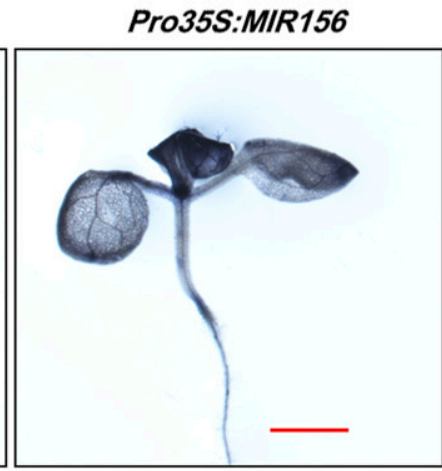

Pro35S:MIM156

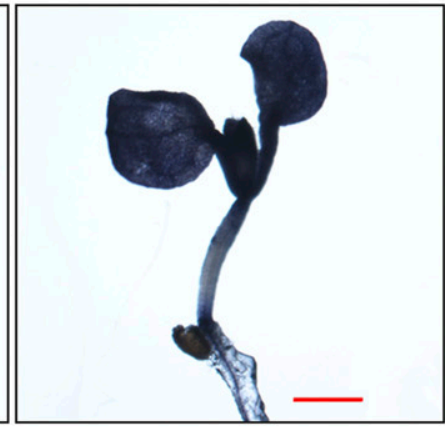

ProSPL9:rSPL9
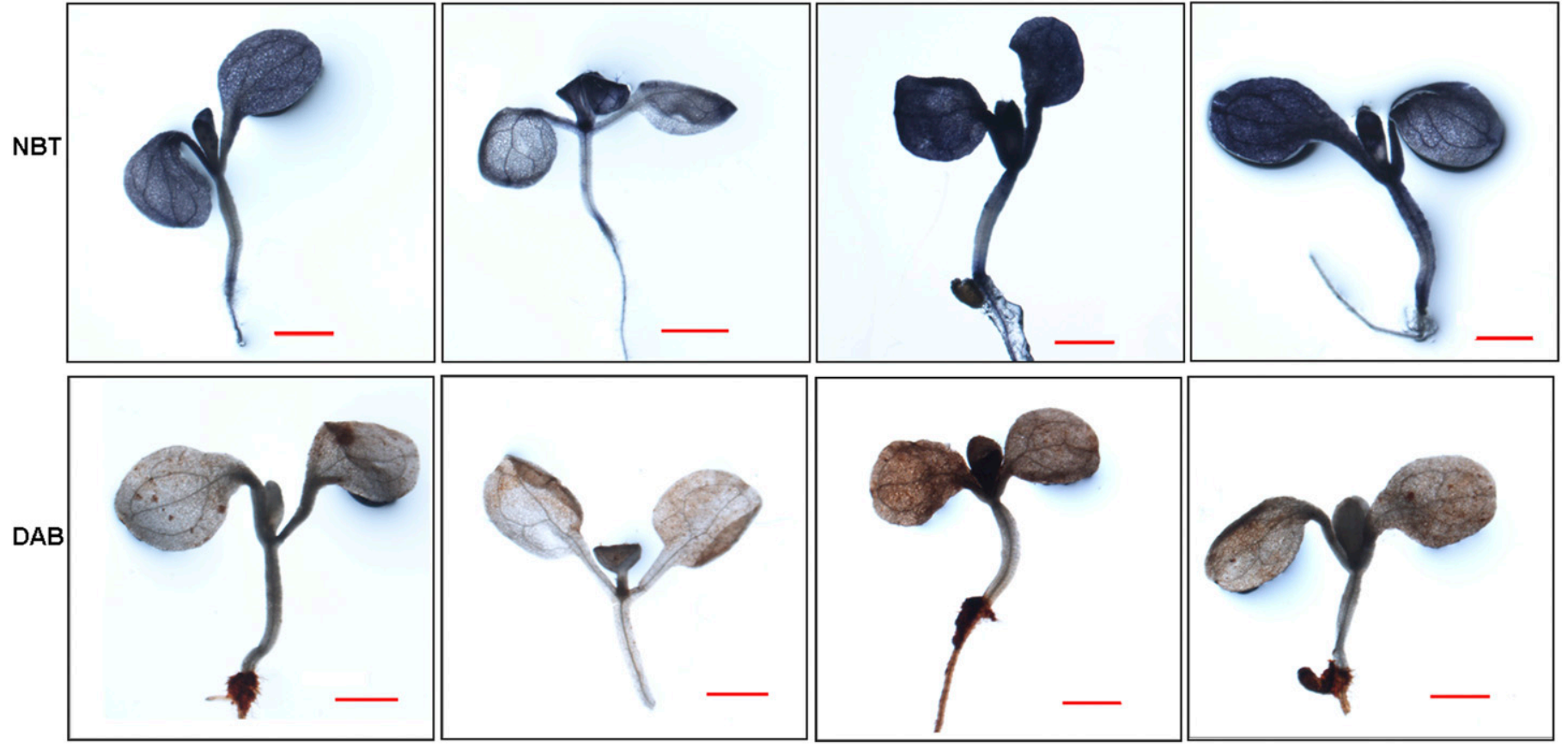

B

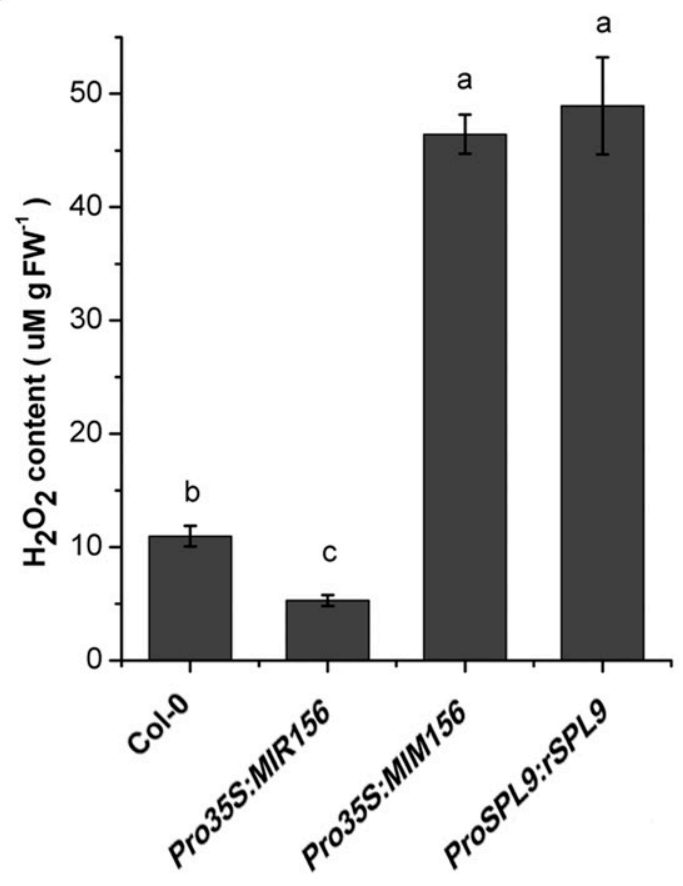

C

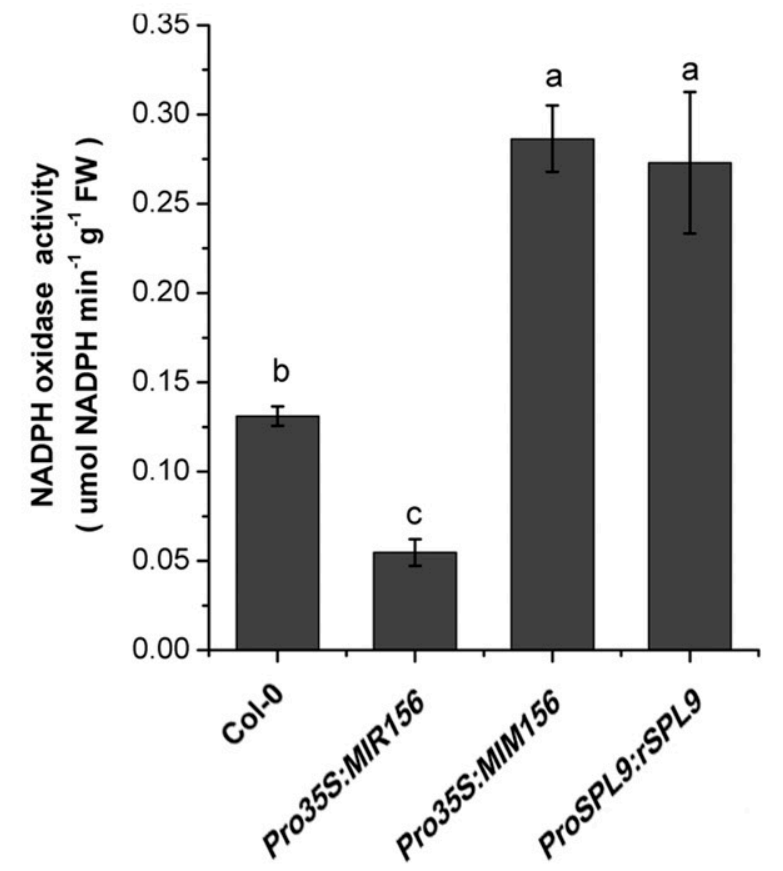

Fig. 1. Reactive oxygen species accumulation in the miR156/SPL9 module. A, In situ detection of leaf $\mathrm{O}_{\overline{2}}^{-}$and $\mathrm{H}_{2} \mathrm{O}_{2}$. Nitroblue tetrazolium (NBT) and 3,3'diaminobenzidine (DAB) stains were used to detect the presence of $\mathrm{O}_{2}^{-}$and $\mathrm{H}_{2} \mathrm{O}_{2}$ in Pro35S:MIR156, Pro35S:MIM156, and ProSPL9:rSPL9 mutants and wild-type Col-0 seedlings. The 1-week-old seedlings were collected and stained. The horizontal bar represents $2 \mathrm{mM}$. B and $\mathbf{C}$, Quantitative measurements of $\mathrm{H}_{2} \mathrm{O}_{2}$ level and NADPH oxidase activity in Col-0 and mutant seedlings. Data represent means \pm standard deviation from three biological replicates. Different letters at the top of each column indicate significant differences at $P \leq 0.05$ by Fisher's least significant difference tests. $\mathrm{FW}=$ fresh weight. 
adjusted to a final concentration of $1 \times 10^{8} \mathrm{CFU} \mathrm{ml}-1$ in sterilized $\mathrm{MgCl}_{2}$ (10 mmol/liter). Leaves 1 and 2 of 5-week-old Arabidopsis were syringe infiltrated with the bacteria. At least five of each mutant plant were used, and $10 \mathrm{mM} \mathrm{MgCl}_{2}$ was used as the mock control. The inoculated plants were kept at $100 \%$ humidity overnight, then raised in a growth chamber under the conditions described above for 3 more days. Disease symptoms in Arabidopsis leaves were observed and photographed. Using the methods described by Katagiri et al. (2002), the number of bacterial populations in four different plants of each genotype was determined. Leaf disks with disease symptoms were ground and suspended in $1 \mathrm{ml}$ of sterilized $\mathrm{MgCl}_{2}(10 \mathrm{mM})$. Leaf extracts were 10-fold serially diluted and plated onto King's B medium supplemented with rifampicin at $50 \mathrm{mg} / \mathrm{liter}$. After incubation at $28^{\circ} \mathrm{C}$ for 2 days, we counted the CFU grown on the plates. To further investigate the role of ROS in miR156/SPL9 module-mediated responses to bacteria, wild-type Col-0 (WT) and Pro35S:MIR156 leaves were sprayed with $10 \mathrm{mM} \mathrm{H}_{2} \mathrm{O}_{2}$ (Sigma) in $0.1 \%$ Triton $\mathrm{X}-10012 \mathrm{~h}$ before being syringe infiltrated with $P$. syringae pv. tomato DC3000; $0.1 \%$ Triton X-100 was used as the mock control.

Statistical analysis. Differences were analyzed using a oneway analysis of variance with Fisher's least significant difference tests. A $P$ value $\leq 0.05$ was considered statistically significant. All analyses were performed using ORIGIN 8.

\section{RESULTS}

Changes in $\mathrm{H}_{2} \mathrm{O}_{2}$ levels caused by the miR156/SPL9 module. ROS act as a second messenger in pathogen interactions and miRNA responses (Camejo et al. 2016; Islam et al. 2018). To determine whether the miR156/SPL9 module affects $\mathrm{H}_{2} \mathrm{O}_{2}$ levels in Arabidopsis, we attempted to detect in situ accumulation of $\mathrm{O}_{2}^{-}$and $\mathrm{H}_{2} \mathrm{O}_{2}$ using NBT and DAB staining methods, respectively. Both methods produced lower levels of staining in Pro35S:MIR156 seedlings compared with that in WT seedlings (Fig. 1A). To exclude the possibility that this was an indirect effect of other miRNAs, we utilized Pro35S:MIM156 plants in which miR156 activity is specifically reduced by constitutive expression of a target mimic (Franco-Zorrilla et al. 2007; Wang and Weigel 2008). Higher levels of staining were observed in Pro35S:MIM156 seedlings relative to that in WT (Fig. 1A). ProSPL9:rSPL9, which is an SPL9 overexpression mutant but insensitive to miR156 action (Wang and Weigel 2008), displayed similar results to Pro35S:MIM156 (Fig. 1A). Similar effects of miR156 and its $S P L 9$ target on $\mathrm{H}_{2} \mathrm{O}_{2}$ content in seedlings were also observed (Fig. 1B). To confirm whether $\mathrm{H}_{2} \mathrm{O}_{2}$ accumulation is affected by increased activity of NADPH oxidase, we measured the activity of NADPH oxidase in extracts of WT and mutant seedlings. Compared with WT plants, NADPH oxidase activity was significantly lower in Pro35S: MIR156 plants but higher in Pro35S:MIM156 and ProSPL9:rSPL9 plants (Fig. 1C). These results indicate that the miR156/SPL9 module plays a role in modulating ROS accumulation.

Involvement of $\mathrm{H}_{2} \mathrm{O}_{2}$ in the miR156/SPL9 module. To explore the underlying molecular mechanisms of the miR156/SPL9 module in $\mathrm{H}_{2} \mathrm{O}_{2}$ accumulation, we firstly examined the expression of genes involved in antioxidant activity using RT-qPCR. Three antioxidant genes (GR, $C A T$, and MDAR 6 ) were downregulated in Pro35S:MIR156 seedlings but upregulated in Pro35S:MIM156 and ProSPL9:rSPL9 seedlings compared with that in WT (Fig. 2). An upregulation of MADR3 was observed only in Pro35S:MIM156 seedlings, whereas minimal changes in expression was detected in Pro35S:MIR156 and ProSPL9:rSPL9 seedlings (Fig. 2).

We also examined the activity of antioxidant enzymes. The activities of SOD, CAT, MDAR, and GR were significantly lower in Pro35S:MIR156 plants but much higher in Pro35S:MIM156 and ProSPL9:rSPL9 plants than that in WT (Fig. 3). POD activity was suppressed in Pro35S:MIR156 seedlings but enhanced in Pro35S: MIM156 plants, while DHAR activity was elevated in Pro35S: MIM156 and ProSPL9:rSPL9 plants. These results further support the role of the miR156/SPL9 module in ROS accumulation.

Involvement of the SA-signaling pathway in the miR156/ SPL9 module. Various hormone pathways have been reported to be involved in miRNA responses (Islam et al. 2018; Vidhyasekaran 2015). $\mathrm{H}_{2} \mathrm{O}_{2}$ and $\mathrm{O}_{2}^{-}$accumulation is always associated with the induced expression of SA-induced pathogenesis-related (PR) proteins in plants (Klessig and Malamy 1994). Based on these reports and the level changes in ROS accumulation detected above, we investigated the expression of SA-responsive genes by RTqPCR. The expression levels of $P R 1$ and $P R 2$ were significantly downregulated in Pro35S:MIR156 seedlings but upregulated in Pro35S:MIM156 and ProSPL9:rSPL9 seedlings compared with that in WT (Fig. 4A). Significant downregulation and upregulation of PR5 were observed in Pro35S:MIR156 and Pro35S:MIM156 seedlings, respectively, whereas upregulation of $P R 4$ was only observed in Pro35S:MIM156 seedlings (Fig. 4A).

The expression of nonexpresser of $P R(N P R)$ genes, which have been reported to be required for SA-induced $P R$ gene expression (Cao et al. 1997; Vernooij et al. 1994), was also detected. As
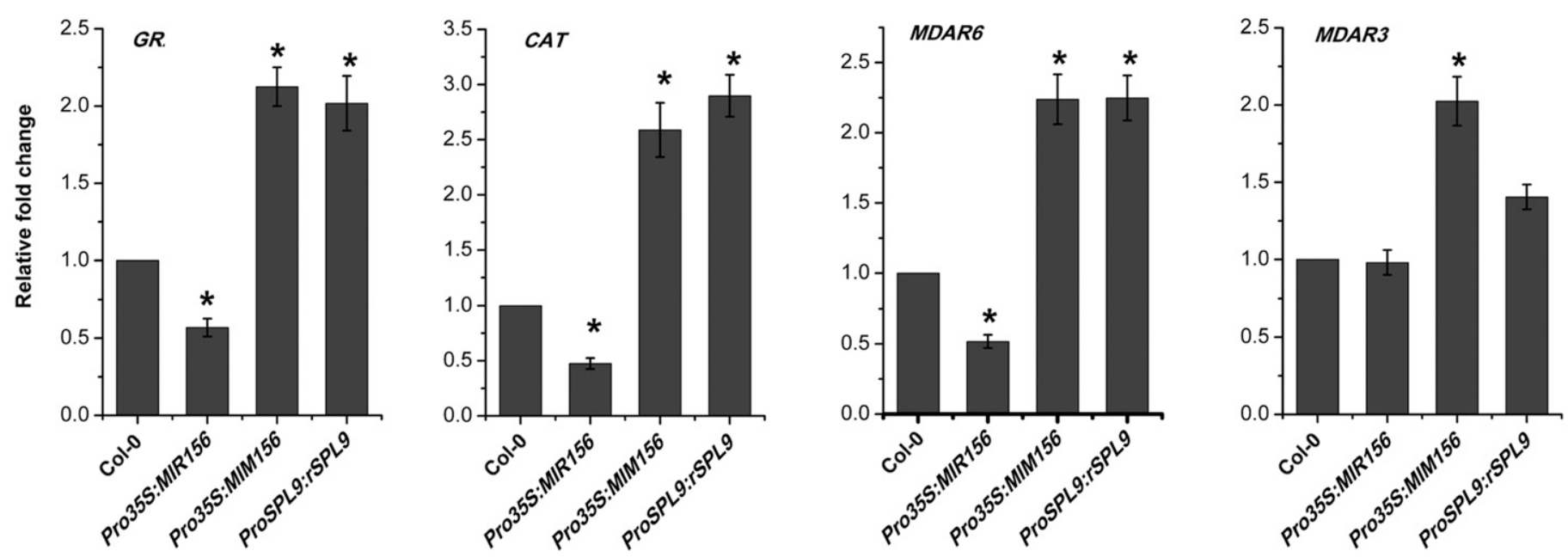

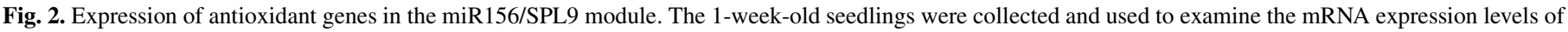

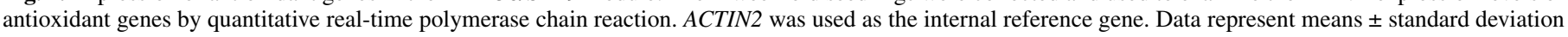

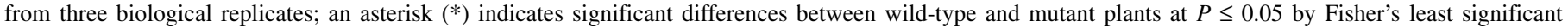
difference tests. $\mathrm{GR}=$ glutathione reductase, $\mathrm{CAT}=$ catalase, and $\mathrm{MDAR}=$ monodehydroascorbate reductase . 
expected, the expression levels of NPRI and NPR3 were lower in Pro35S:MIR156 seedlings but higher in Pro35S:MIM156 and ProSPL9:rSPL9 seedlings relative to that in WT (Fig. 4). Significant downregulation and upregulation of NPR5 were observed in Pro35S: MIR156 and Pro35S:MIM156 mutants, respectively, whereas only small differences in expression were observed in ProSPL9:rSPL9 seedlings (Fig. 4B). In addition, we observed that the same expression patterns of SA-responsive genes were present in juvenile leaves of the indicated mutants plants (Fig. 4C and D). Taken together, our results suggest that the miR156/SPL9 module controls the activation or inactivation of the SA signaling pathway.

Effect of the miR156/SPL9 module in disease response. The elevated production of ROS and activation of the SA signaling pathway implicates an immune function of the miR156/SPL9 module. To test this, a virulent $P$. syringae pv. tomato DC3000 strain (Whalen et al. 1991) was chosen to determine whether the miR156/SPL9 module affects plant responses to bacterial infection. We inoculated WT and transgenic plants with P. syringae pv. tomato DC3000 by syringe infiltration, and the progress of infection was observed over 4 days postinoculation (dpi). Pro35S:MIR156 leaves displayed a broader area with disease symptoms compared with WT (Fig. 5A). In contrast, Pro35S:MIM156 and ProSPL9:rSPL9 leaves displayed milder symptoms compared with WT. To confirm whether bacterial proliferation inside the plants was in accordance with disease symptoms, bacterial growth was measured in WT and mutant plants at 4 dpi. Consistent with the visible symptoms, Pro35S:MIR156 plants exhibited significantly higher bacterial population than WT at $4 \mathrm{dpi}$, whereas Pro35S:MIM156 and ProSPL9:rSPL9 plants exhibited significantly lower bacterial proliferation (Fig. 5B). These results indicate that Pro35S:MIR156 is more susceptible to P. syringae pv. tomato DC3000, while Pro35S:MIM156 and ProSPL9:rSPL9 are more resistant to $P$. syringae pv. tomato DC3000 than WT.

To confirm that the SA signaling pathway mediated by the miR156/SPL9 module was involved in the immune system responses, we evaluated the levels of $P R I$ and $N P R 1$ transcripts. After bacterial challenge, the $P R I$ and $N P R I$ transcript levels were
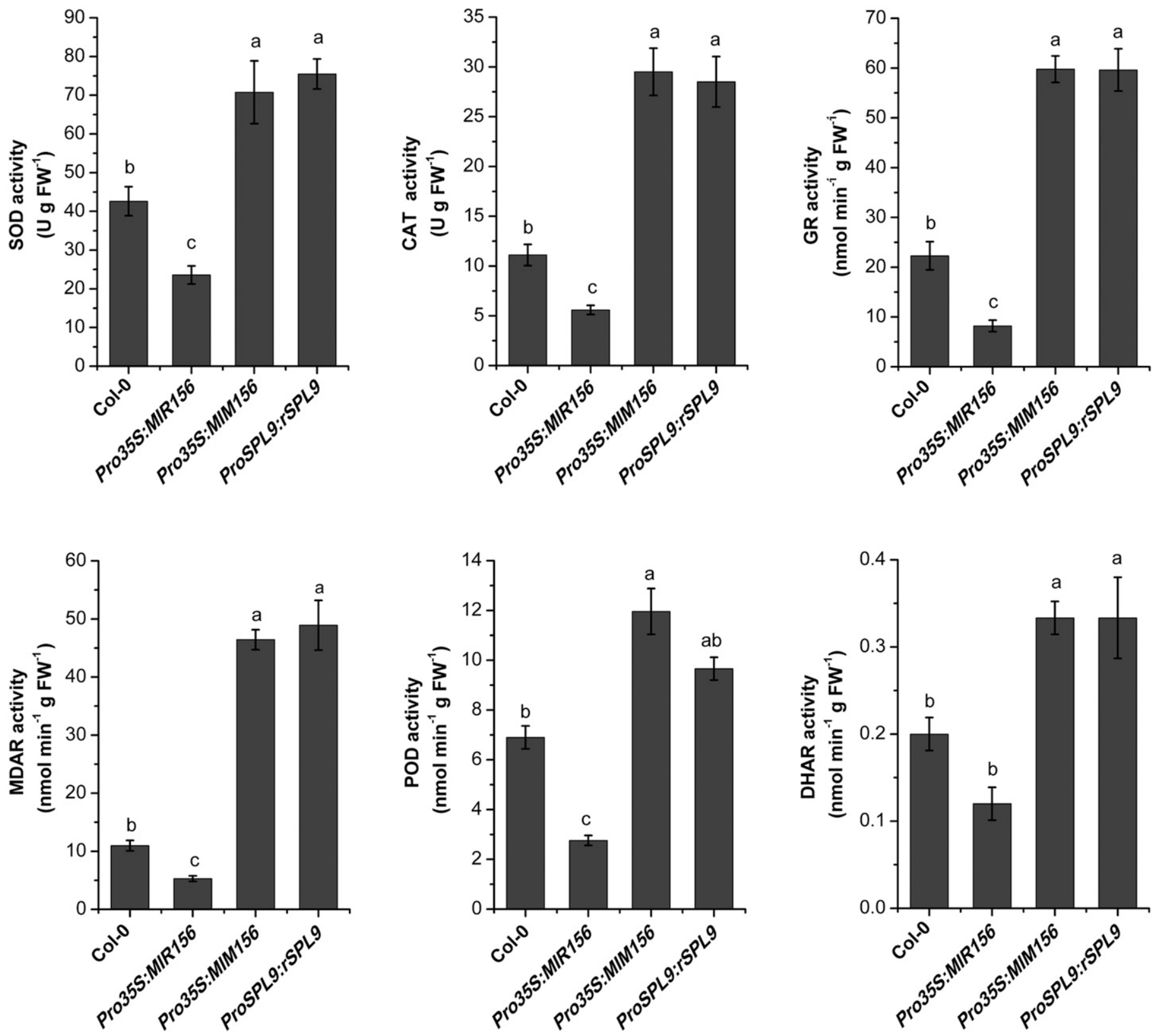

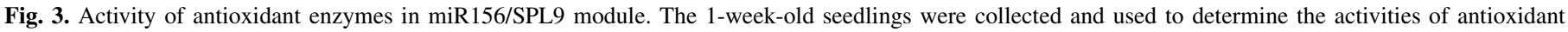

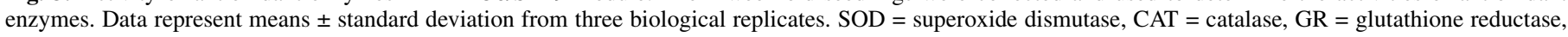

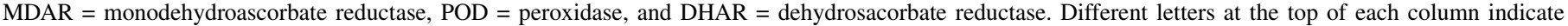
significant differences at $P \leq 0.05$ by Fisher's least significant difference tests. $\mathrm{FW}=$ fresh weight. 
increased 750- and 32-fold, respectively, in WT (Fig. 5C and D). The levels of these genes in Pro35S:MIR156 (410- and 17-fold, respectively) were much lower whereas, in Pro35S:MIM156 (1,368- and 103-fold, respectively) and ProSPL9:rSPL9 $(1,208$ and 81 -fold, respectively), these levels were dramatically increased compared with that in WT (Fig. 5C and D). Consequently, the shift in resistance ability of the indicated mutants to bacterial challenge is likely due to suppression or activation of the SA signaling pathway.

Ablation of miR156-mediated bacterial susceptibility by $\mathbf{H}_{2} \mathrm{O}_{2}$. To further investigate the role of ROS in the miR156/SPL9 module-mediated immunity to bacteria, we treated WT and Pro35S: MIR156 leaves with $10 \mathrm{mM} \mathrm{H}_{2} \mathrm{O}_{2} ; 0.1 \%$ Triton $\mathrm{X}-100$ was used as a mock control and, $12 \mathrm{~h}$ after treatment, leaves were syringe infiltrated with $P$. syringae pv. tomato DC3000. Four days later, we observed milder leaf symptoms and detected lower levels of bacterial population in WT and Pro35S:MIR156 plants treated with $\mathrm{H}_{2} \mathrm{O}_{2}$ compared with the mock control (Fig. 6). However, Pro35S: MIR156 plants still exhibited significantly higher levels of bacterial growth compared with WT (Fig. 6B). These results suggest that $\mathrm{H}_{2} \mathrm{O}_{2}$ enhanced resistance in Arabidopsis and masked the effect of miR156 on susceptibility to $P$. syringae pv. tomato DC3000 infection.

To determine whether the effect of ROS in responses to bacterial infection is related to the SA signaling pathway, we treated WT and Pro35S:MIR156 plants with $\mathrm{H}_{2} \mathrm{O}_{2}$ for $12 \mathrm{~h}$. The expression of SA signaling genes was significantly increased in the treated plants compared with the mock controls (Fig. 7). In Pro35S:MIR156 plants, the transcript levels of SA-responsive genes were less affected than that in WT after $\mathrm{H}_{2} \mathrm{O}_{2}$ treatment (Fig. 7). These results suggest that the ablation of miR156-induced susceptibility to P. syringae pv. tomato DC3000 infection by $\mathrm{H}_{2} \mathrm{O}_{2}$ was due to activation of the SA signaling pathway.

\section{DISCUSSION}

Recent studies have revealed a number of miRNAs involved in responses to pathogens, and artificial miRNAs have been designed as new strategies for disease control (Islam et al. 2018). Overexpression of miR160a and miR398b enhances resistance to blast fungus $M$. oryzae in rice, and overexpression of miR393 increases resistance to P. syringae in Arabidopsis (Li et al. 2013; Navarro and Jones 2006). However, upregulation of miR773 and miR398b induce susceptibility to $P$. syringae pv. tomato DC3000 in Arabidopsis, and upregulation of miR528 also induces susceptibility to Rice strip virus in rice ( $\mathrm{Li}$ et al. 2013; Wu et al. 2017). Furthermore, suppression of nbe-miR166h-p5 attenuated the leaf yellowing symptom of Turnip mosaic virus and Potato virus $\mathrm{X}$ in $N$. benthamiana, and decreased viral accumulation (Wang et al. 2018). These findings imply that miRNAs play a complex role in regulating immunity depending on the type of pathogen and plant species involved. Here, we found that overexpression of miR156 (Pro35S:MIR156 plants) increased susceptibility to $P$. syringae pv. tomato DC3000 infection, while interference with miR156 activity by target mimics (Pro35S:MIM156 plants) conferred considerable resistance to bacterial attack (Fig. 5A and B). Therefore, miR156 might play a negative role in regulating plant immunity. Furthermore, we demonstrated that upregulation of the miR156 target gene SPL9 (ProSPL9:rSPL9 plants) elevated resistance to P. syringae pv. tomato DC3000 infection (Fig. 5A and B), which is consistent with the previously reported positive immune function of AtSPL6 and NbSPL6 (Padmanabhan et al. 2013). However, their specific mechanisms may be different. Nucleotide-binding domain leucine-rich repeats interact with NbSPL6 only during an active defense response, whereas AtSPL6 acts only against the bacterial pathogen $P$. syringae expressing the AvrRps4 effector but not avrRpm 1 and avrRpt 2 effectors (Padmanabhan et al. 2013). Our data showed that ProSPL9:rSPL9 plants exhibited constitutive systemic acquired resistance, including elevated ROS levels and increased SA signaling pathway transcripts, resulting in an enhanced resistance of $P$. syringae pv. tomato DC3000 infection (Figs. 1, 2, 3, 4, and 5; Supplementary Figs. S2, S3, and S4). In plants, age-related resistance is a common phenomenon, because old and mature plants may display enhanced resistance to attacks by pathogens and herbivores (Kus et al. 2002; Price 1991). SPL transcripts gradually increase during the transition to flowering due to the decline of miR156 levels along with plant growth (Wang et al. 2009; Wu and Poethig 2006; Wu et al. 2009). Cumulative accumulation of glucosinolates compensates for miR156-targeted
A
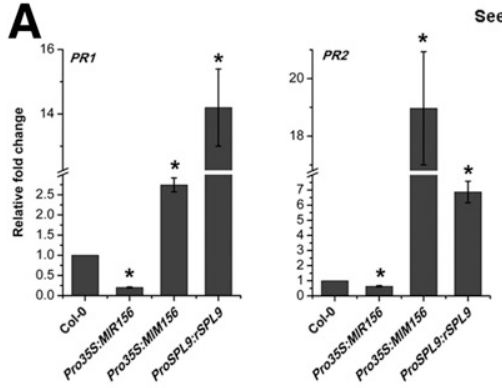

Seedlings
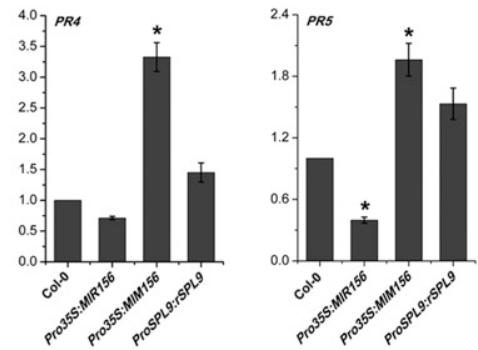

C
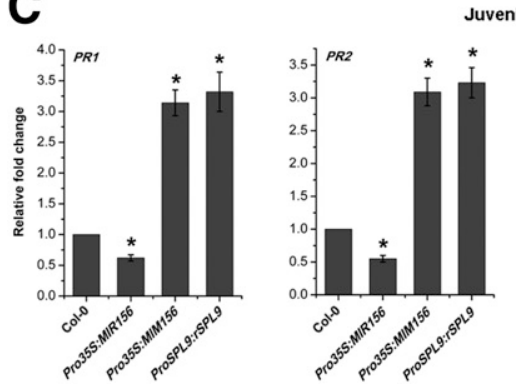

Juvenile leaves
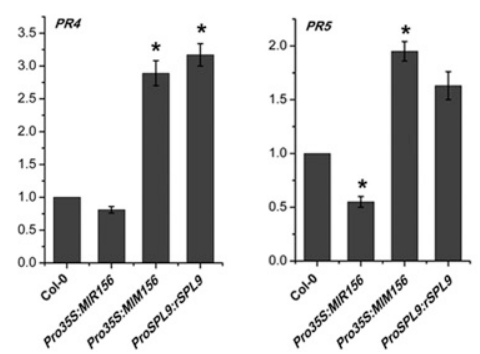

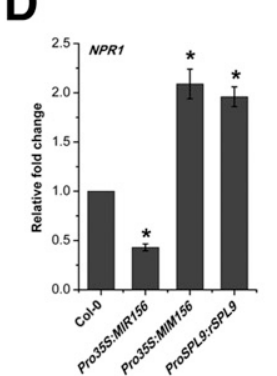

B
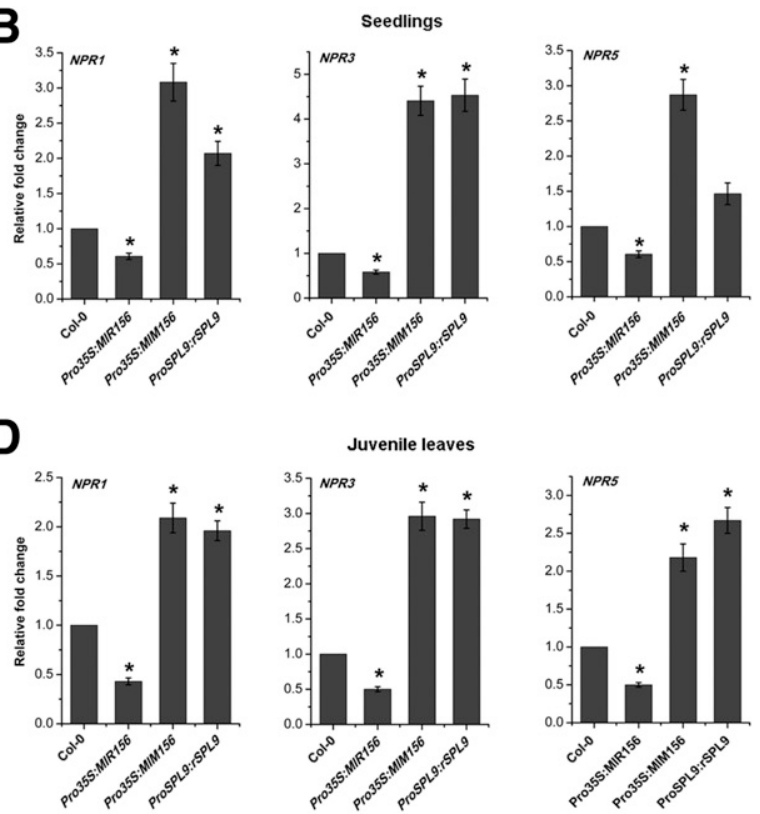

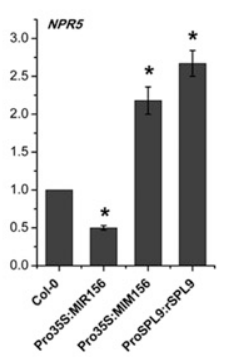

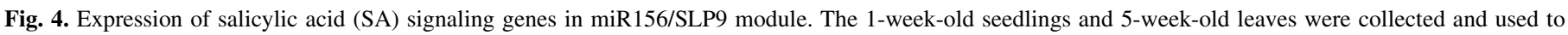

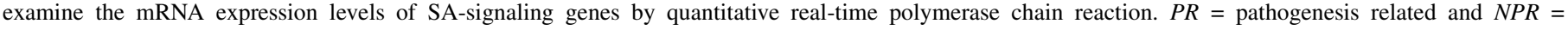

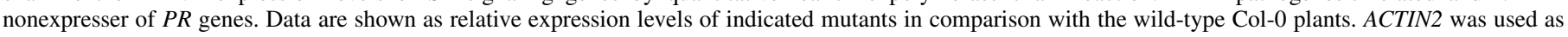

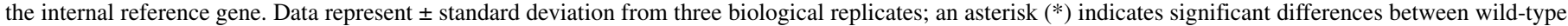
and mutant plants at $P \leq 0.05$ by Fisher's least significant difference tests. 
SPL9 regulated age-dependent decline of JA-induced insect resistance in adult plants (Mao et al. 2017). Therefore, the agerelated miR156-targeted SPL9 may also contribute to the immunosenescence in plants.

According to the previous studies, miRNAs are involved in regulating ROS release (Jia et al. 2017; Lu et al. 2011; Wu et al. 2017), and elevated ROS accumulation is observed following abiotic (drought, cold, heat, high-light, wound, and heavy-metal) and biotic (bacteria, fungi, and viruses) stress in plants (Camejo et al. 2016; Gechev et al. 2006; Yang et al. 2017). Under cold stress, $N$. benthamiana leaves transiently overexpressing miR156 exhibit lower $\mathrm{H}_{2} \mathrm{O}_{2}$ accumulation (Yang et al. 2017). In apple, the MdMIR156a5 and MdMIR156a12 transcriptional regulatory network controls the vegetative phase change in response to the plastid-nucleus redox signals such as glutathione (GSH). However, MdMIR156a6-overexpressing or miR156-mimetic transgenic $N$. benthamiana showed no regular differences in ROS and GSH levels (Du et al. 2015; Jia et al. 2017). In this work, we found that overexpression of miR156 could reduce ROS accumulation, whereas specific repression of miR156 activity increased ROS levels (Fig. 1), indicating that miR156 may negatively regulate ROS levels in Arabidopsis. Similarly, previous reports have documented that miR398 and miR528 also negatively regulate ROS levels by targeting and repressing expression of their target genes (Leng et al. 2017; $\mathrm{Lu}$ et al. 2011; Wu et al. 2017). Cu or $\mathrm{Zn}$ superoxide dismutases (CSD1 and CSD2), targets of miR398, catalyze the conversion of $\mathrm{O}_{\overline{2}}$ to $\mathrm{H}_{2} \mathrm{O}_{2}$ and $\mathrm{O}_{2}$, directly detoxifying ROS generated in the cytoplasm and chloroplasts (Lu et al. 2011; Perry et al. 2010). L-ascorbate oxidase, a target of miR528, plays a direct role in regulating basal ROS levels by oxidizing apoplastic L-ascorbic acid (Pignocchi et al. 2006; Wu et al. 2017). Our data showed that overexpression of SPL9 increased levels of $\mathrm{O}_{\overline{2}}$ and $\mathrm{H}_{2} \mathrm{O}_{2}$ observed by situ staining, higher $\mathrm{H}_{2} \mathrm{O}_{2}$ content, and elevated NADPH oxidase activity (Fig. 1), suggesting that SPL9 may play a
A
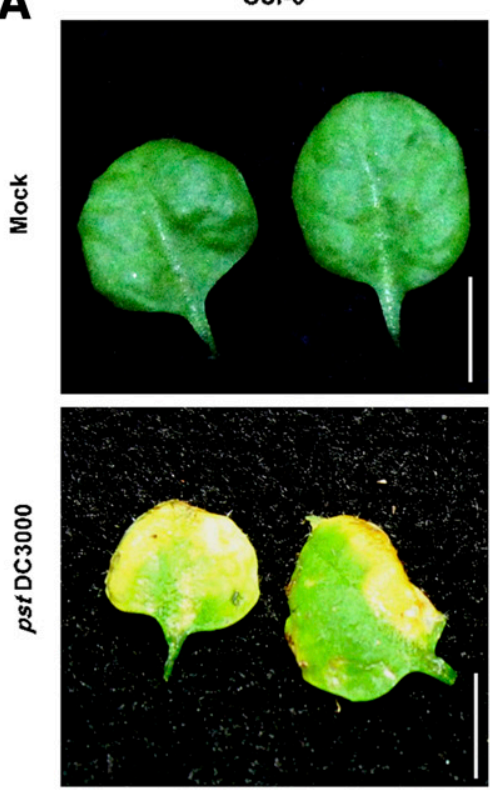

Pro35S:MIR156
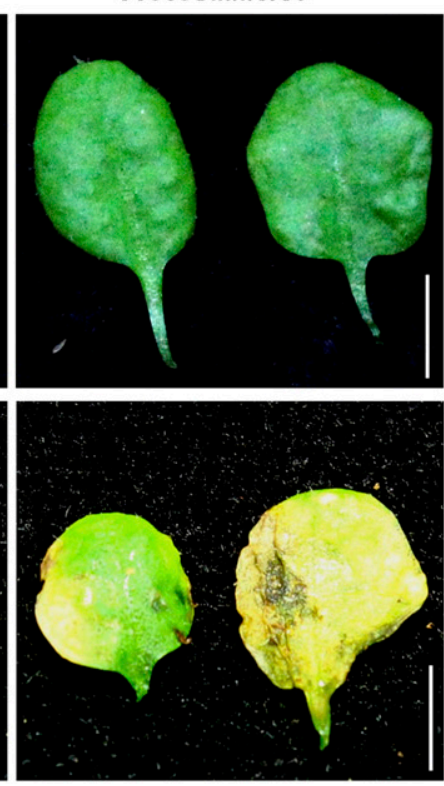

Pro35S:MIM156
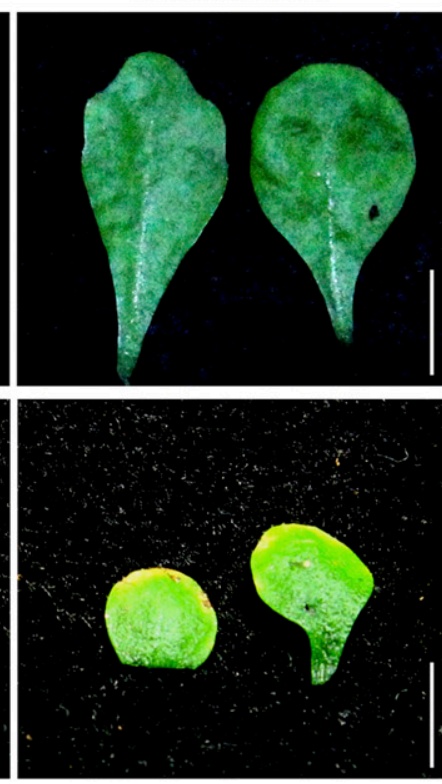

\section{ProSPL9:rSPL9}
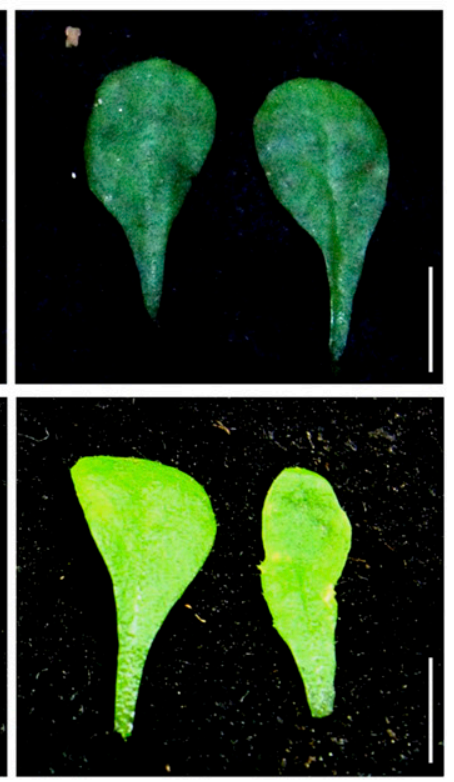

B

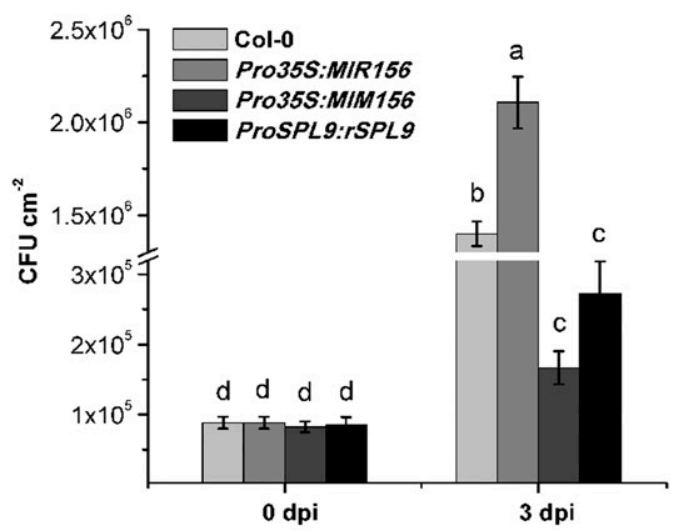

C

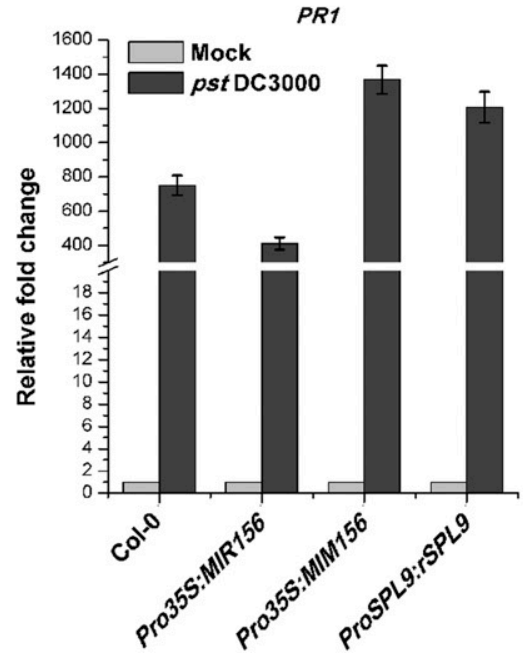

D

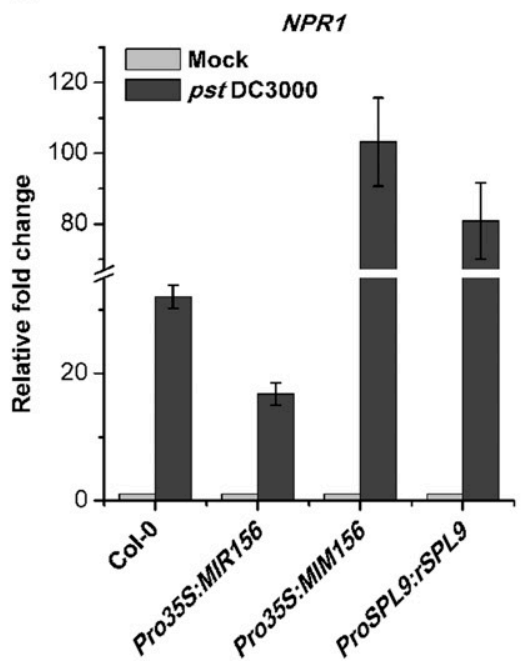

Fig. 5. Effect of miR156/SPL9 module in response to bacteria infection. A, Disease symptoms on Arabidopsis leaves caused by Pseudomonas syringae pv. tomato DC3000 infection. Leaves were 5 weeks old and syringe infiltrated with a bacterial suspension $\left(1 \times 10^{8} \mathrm{CFU}\right.$ in sterilized $\left.10 \mathrm{mM} \mathrm{MgCl}_{2}\right)$ of $P$. syringae pv. tomato DC3000. $\mathrm{MgCl}_{2}(10 \mathrm{mM})$ without bacteria was syringe infiltrated as mock control. Photos of the disease symptoms were taken after 4 days postinoculation (dpi). The white bar represents 1 centimorgan. B, Number of CFU after 4 dpi. Different letters at the top of each column indicate significant differences at $P \leq 0.05$ by Fisher's least significant difference tests. C, $P R 1$ and D, NPRI expression in the Col-0 and mutants after infection. Error bars represent the standard error of three biological repeats. 
positive role in regulating ROS accumulation. In addition, we also observed the opposite effects of miR156 and its SPL9 target on the expression and activity of antioxidant enzymes (Figs. 2 and 3). Plants have different ROS level at different ages (Camejo et al. 2016; Gechev et al. 2006). Consistent with previous studies (Du et al. 2015; Jia et al. 2017), we found that the levels of ROS in juvenile leaves were higher than those in young seedlings (Figs. 1, 2, and 3). Furthermore, our data showed that the levels of ROS accumulation in juvenile WT plants and indicated mutants displayed the same change patterns as those in young seedlings (Figs. 1, 2, and 3). Thus, the negative regulation of miR156 on ROS accumulation may depend on the transcription function of SPL9 indirectly but not directly on miR156 itself .

ROS has been demonstrated to be involved in responses to plant pathogen invasion (Camejo et al. 2016; Klessig and Malamy 1994). By inducing defense-related gene expression, increased $\mathrm{H}_{2} \mathrm{O}_{2}$ accumulation causes enhanced resistance to Erwinia carotovora subsp. carotovora, Phytophthora infestans race $0, P$. capsici, and
Pseudomonas syringae pv. tomato DC3000 infection (Wang et al. 2013; Wu et al. 1995). ROS accumulation has also been shown to be directly modulated by miRNAs and to contribute to defenses against pathogen infection (Pignocchi et al. 2006; Wu et al. 2017). Here, we demonstrated that levels of ROS accumulation are positively correlated with susceptibility to $P$. syringae pv. tomato DC3000 (Figs. 1, 2, 3, and 5). We also proved that exogenous application of $\mathrm{H}_{2} \mathrm{O}_{2}$ attenuated leaf symptoms and reduced bacterial proliferation during $P$. syringae pv. tomato DC3000 infection (Fig. 6). In addition, we confirmed that miR156 suppressed the ability of $\mathrm{H}_{2} \mathrm{O}_{2}$ to enhance resistance to bacterial infection (Fig. 6). Although the details of SPL9 on regulating ROS accumulation require further investigation, our data suggest that ROS-mediated defense may, at least partially, contribute to the miR156/SPL9 module-regulated immune system.

miRNAs have also been reported to target genes involved in hormone pathways such as JA and auxin pathways (Mao et al. 2017; Navarro and Jones 2006; Zhang et al. 2011, Zhang et al. 2016).
A
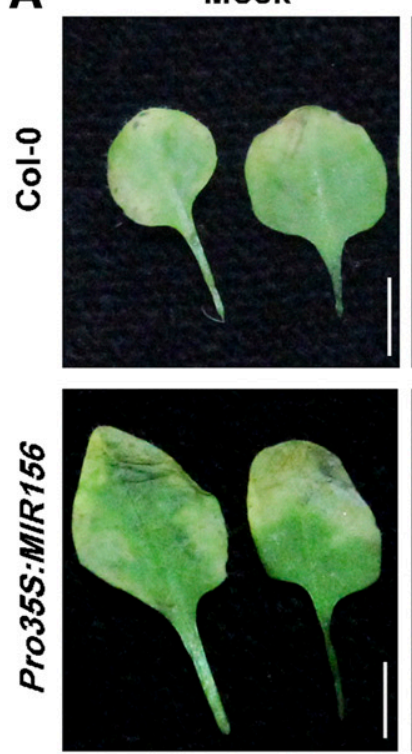
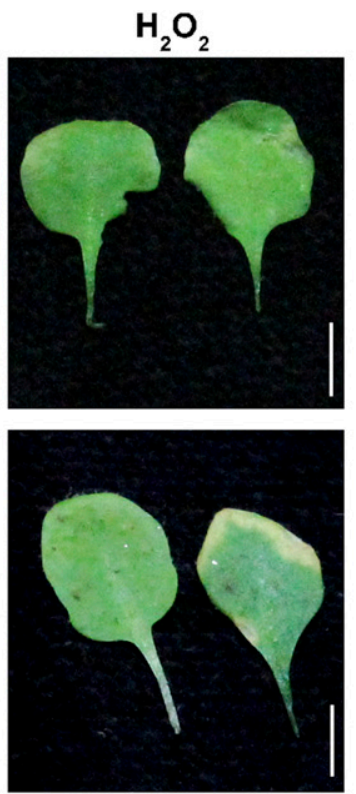

B

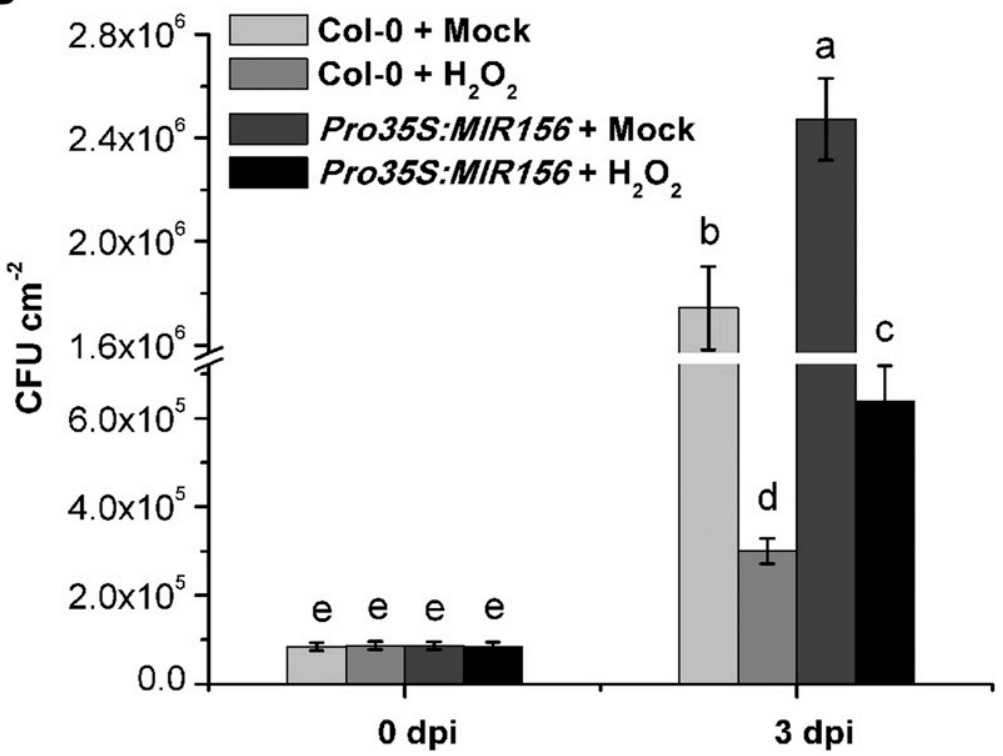

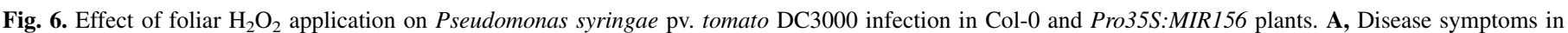

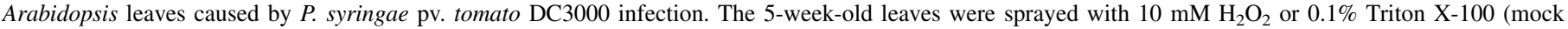

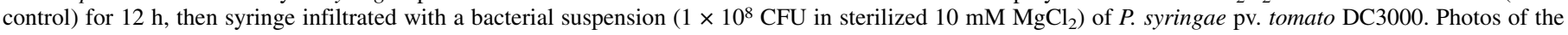

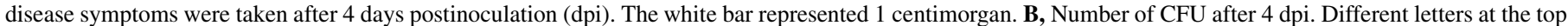
of each column indicate significant differences at $P \leq 0.05$ by Fisher's least significant difference tests.
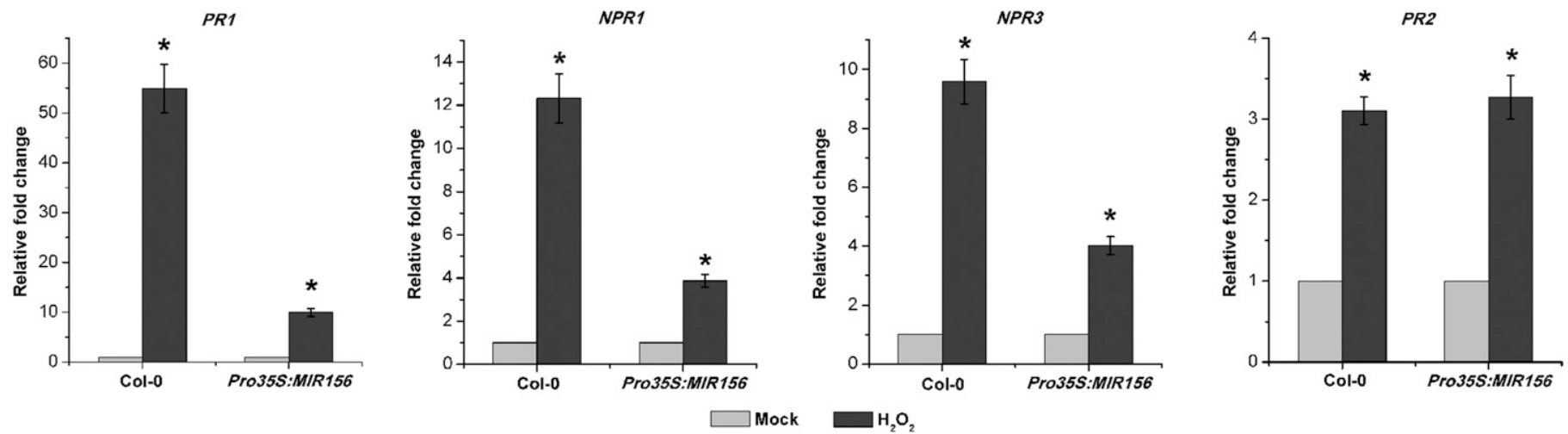

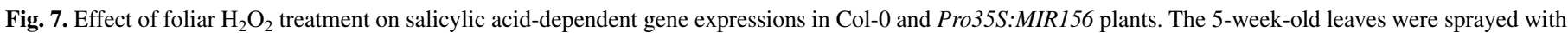

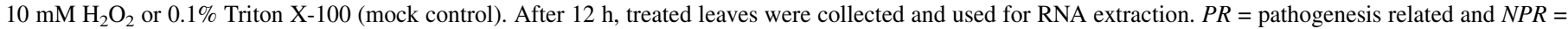

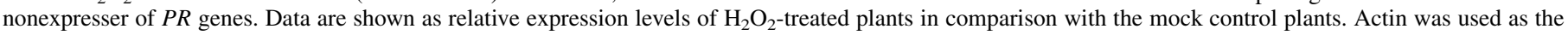

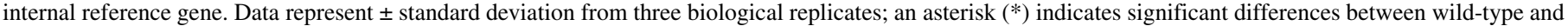
mutant plants at $P \leq 0.05$ by Fisher's least significant difference tests. 
miR319 decreases endogenous JA levels and downregulates expression of JA biosynthesis- and signaling-related genes in rice (Zhang et al. 2016) by targeting TEOSINTE BRANCHED/CYCLOIDEA/ $P C s F$ genes. miR156-targeted SPL9 negatively regulates JA response through interaction with JAZ proteins in Arabidopsis (Mao et al. 2017). It has been well known that cross-talk between SA and JA pathways displays antagonistic effects on pathogen attack (Kim et al. 2013; Petersen et al. 2000; Spoel et al. 2003). Arabidopsis NahG plants, which are defective in accumulating SA, produce higher JA levels and expression of JA-responsive genes upon $P$. syringae pv. tomato DC3000 infection (Spoel et al. 2003). In contrast, the mpk4 mutant, exhibiting elevated SA levels and constitutive $P R$ gene expression but decreased JA-responsive gene expression, increases resistance to $P$. syringae pv. tomato DC3000 infection (Petersen et al. 2000). Here, we found suppression of $P R$ gene transcripts in the Pro35S:MIR156 mutants but significant increases in their expression in the Pro35S:MIM156 and ProSPL9: rSPL9 plants (Fig. 4). The expression of NPR genes, master regulators of SA-induced $P R$ gene expression (Ding et al. 2018), displayed the same changes in expression as the $P R$ genes in indicated plants (Fig. 4). Unexpectedly, we observed no significant effect of miR156/SPL9 module on SA accumulation (Supplementary Fig. S5). Nevertheless, we found that suppression SA signaling transcripts in Pro35S:MIR156 plants caused susceptibility to the $P$. syringae pv. tomato DC300 pathogen, whereas activation of the SA pathway in Pro35S:MIM156 and ProSPL9:rSPL9 plants enhanced pathogen resistance (Figs. 4 and $5 \mathrm{~A}$ and $\mathrm{B}$ ). In addition, we also demonstrated that the resistance ability of the indicated mutants was accompanied by different transcript levels of $P R l$ and $N P R 1$ following bacterial challenge (Fig. 5C and D). These results are similar to those of previous studies, which found that elevated expression of SA marker genes such PRI and NPRl is often associated with enhanced disease resistance in Arabidopsis (Chen et al. 1993; Hondo et al. 2007; Rogers and Ausubel 1997, Wu et al. 2012). Taken together, the results suggest that activation of SA signaling and suppression of JA signaling play an important role in the miR156/SPL9 module-mediated immune defense to pathogen infection, which also provides new evidence that plants infected by SA-inducing biotrophic pathogens often suppress JA-dependent defense responses (Spoel et al. 2007; Vidhyasekaran 2015).

A recent study reported crosstalk between ROS- and SAdependent pathways, leading to pathogen resistance (Karpiński et al. 2013). Similarly, our data analysis revealed that the levels of ROS accumulation were in keeping with the basal expression of SA signaling pathway genes (Figs. 1, 2, 3, and 4), indicating a tight interaction between these two independent pathways. To further investigate the role of ROS and SA signaling pathways in miR156/ SPL9 module-mediated defense responses to bacterial infection, we treated WT and Pro35S:MIR156 plants with exogenous $\mathrm{H}_{2} \mathrm{O}_{2} \cdot \mathrm{H}_{2} \mathrm{O}_{2}$ treatment ablated miR156-induced $P$. syringae pv. tomato DC3000 susceptibility (Fig. 6). Exogenous $\mathrm{H}_{2} \mathrm{O}_{2}$ treatment efficiently induced the expression of SA signaling pathway genes (Fig. 7). In addition, the induced levels of SA-dependent gene transcripts evoked by exogenous $\mathrm{H}_{2} \mathrm{O}_{2}$ are positively correlated with plant defense to $P$. syringae pv. tomato DC3000 infection (Figs. 6 and 7). These data indicate that $\mathrm{H}_{2} \mathrm{O}_{2}$-mediated defense can ablate miR156-induced susceptibility to $P$. syringae pv. tomato DC3000 infection by activating the SA signaling pathway. This follows the pattern seen in recent studies that ROS acts synergistically with the SA pathway during pathogen infection (Camejo et al. 2016; Gechev et al. 2006; Vidhyasekaran 2015). SA inhibits CAT activity and thereby causes an increase in $\mathrm{H}_{2} \mathrm{O}_{2}$ levels, triggering the expression of defense-related genes during pathogen invasion (Klessig and Malamy 1994). In tobacco, SA enhances ROS levels by binding to an SA-binding protein, SABP3, to mediate a hypersensitive response to disease (Slaymaker et al. 2002). Enhanced ROS levels have also been reported to induce SA-induced $P R$ gene expression and trigger resistance to pathogen invasion (Chaouch et al. 2010;
Rojas et al. 2012). In cat2 mutants overproducing $\mathrm{H}_{2} \mathrm{O}_{2}$, SA accumulation is induced and signaling pathways are activated in response to $P$. syringae pv. tomato DC3000 infection (Chaouch et al. 2010). In N. benthamiana and Arabidopsis, $\mathrm{H}_{2} \mathrm{O}_{2}$ generated by glycolate oxidase activates the SA signal pathway, leading to increased resistance to nonhost pathogens (Rojas et al. 2012). Consistent with the concept of mutual synergistic effects between ROS and SA, our findings enhance the case for crosstalk between ROS and SA pathways in response to bacterial infection in the miR156/SPL9 module.

In conclusion, we have demonstrated that ROS accumulation and SA signaling gene expression were suppressed in miR156 overexpression mutants but elevated in miR156 suppression mutants and SPL9 overexpression mutants. As a result, miR156 induced susceptibility to $P$. syringae pv. tomato DC3000 infection, while $S P L 9$ played an active role in antibacterial immunity in Arabidopsis. Furthermore, foliar $\mathrm{H}_{2} \mathrm{O}_{2}$ treatment triggered activation of the SA signaling pathway, leading to masking of the miR156-mediated $P$. syringae pv. tomato DC3000 susceptibility. Taken together, our results provide new insights into the immune functions of the miR156/SPLs network, which appear to involve regulation of ROS accumulation and activation of the SA signaling pathway.

\section{ACKNOWLEDGMENTS}

We thank J. Wang (Institute for Plant Physiology and Ecology, Shanghai Institute for Biological Sciences, Chinese Academy of Sciences, Shanghai, China) for providing Pro35S:MIR156, Pro35S:MIM156, and ProSPL9: $r S P L 9$ seed.

\section{LITERATURE CITED}

Arshad, M., Feyissa, B. A., Amyot, L., Aung, B., and Hannoufa, A. 2017. MicroRNA156 improves drought stress tolerance in alfalfa (Medicago sativa) by silencing SPL13. Plant Sci. 258:122-136.

Axtell, M. J., and Bowman, J. L. 2008. Evolution of plant microRNAs and their targets. Trends Plant Sci. 13:343-349.

Bai, F., Reinheimer, R., Durantini, D., Kellogg, E. A., and Schmidt, R. J. 2012. TCP transcription factor, BRANCH ANGLE DEFECTIVE 1 (BAD1), is required for normal tassel branch angle formation in maize. Proc. Natl. Acad. Sci. USA 109:12225-12230.

Baulcombe, D. 2004. RNA silencing in plants. Nature 431:356-363.

Bhogale, S., Mahajan, A. S., Natarajan, B., Rajabhoj, M., Thulasiram, H. V., and Banerjee, A. K. 2014. MicroRNA156: A potential graft-transmissible MicroRNA that modulates plant architecture and tuberization in solanum tuberosum ssp. andigena. Plant Physiol. 164:1011-1027.

Camejo, D., Guzmáncedeño, Á., and Moreno, A. 2016. Reactive oxygen species, essential molecules, during plant-pathogen interactions. Plant Physiol. Biochem. 103:10-23.

Cao, H., Glazebrook, J., Clarke, J. D., Volko, S., and Dong, X. 1997. The Arabidopsis NPRl gene that controls systemic acquired resistance encodes a novel protein containing ankyrin repeats. Cell 88:57-63.

Chance, B., and Maehly, A. C. 1955. Assay of catalases and peroxidases. Methods Enzymol. 2:764-775.

Chaouch, S., Queval, G., Vanderauwera, S., Mhamdi, A., Vandorpe, M., Langloismeurinne, M., Breusegem, F. V., Saindrenan, P., and Noctor, G. 2010. Peroxisomal hydrogen peroxide is coupled to biotic defense responses by isochorismate synthase 1 in a daylength-related manner. Plant Physiol. 153:1692-1705.

Chen, Z., Ricigliano, J. W., and Klessig, D. F. 1993. Purification and characterization of a soluble salicylic acid-binding protein from tobacco. Proc. Natl. Acad. Sci. USA 90:9533-9537.

Chuck, G., Cigan, A. M., Saeteurn, K., and Hake, S. 2007. The heterochronic maize mutant Corngrass1 results from overexpression of a tandem microRNA. Nat. Genet. 39:544-549.

Ding, Y., Sun, T., Ao, K., Peng, Y., Zhang, Y., Li, X., and Zhang, Y. 2018. Opposite roles of salicylic acid receptors NPR1 and NPR3/NPR4 in transcriptional regulation of plant immunity. Cell 173:1454-1467.

Du, Z., Jia, X. L., Wang, Y., Wu, T., Han, Z. H., and Zhang, X. Z. 2015. Redox homeostasis and reactive oxygen species scavengers shift during ontogenetic phase changes in apple. Plant Sci. 236:283-294.

Foyer, C. H., and Halliwell, B. 1976. The presence of glutathione and glutathione reductase in chloroplasts: A proposed role in ascorbic acid metabolism. Planta 133:21-25. 
Franco-Zorrilla, J. M., Valli, A., Todesco, M., Mateos, I., Puga, M. I., Rubio-Somoza, I., Leyva, A., Weigel, D., García, J. A., and Paz-Ares, J. 2007. Target mimicry provides a new mechanism for regulation of microRNA activity. Nat. Genet. 39:1033-1037.

Fu, J., Chu, J. F., Sun, X., Wang, J. D., and Yan, C. Y. 2012. Simple, rapid, and simultaneous assay of multiple carboxyl containing phytohormones in wounded tomatoes by UPLC-MS/MS using single SPE purification and isotope dilution. Anal. Sci. 28:1081-1087.

Gechev, T. S., Van, B. F., Stone, J. M., Denev, I., and Laloi, C. 2006. Reactive oxygen species as signals that modulate plant stress responses and programmed cell death. BioEssays 28:1091-1101.

Gestelen, P. V., Asard, H., and Caubergs, R. J. 1997 Solubilization and separation of a plant plasma membrane NADPH-O ${ }^{2-}$ synthase from Other NAD(P)H oxidoreductases. Plant Physiol. 115:543-550.

Gou, J. Y., Felippes, F. F., Liu, C. J., Weigel, D., and Wang, J. W. 2011. Negative regulation of anthocyanin biosynthesis in Arabidopsis by a miR156-targeted SPL transcription factor. Plant Cell 23:1512-1522.

He, Y. Q., Zhang, H. H., Sun, Z. T., Li, J. M., Hong, G. J., Zhu, Q. S., Zhou, X. B., MacFarlane, M., Yan, F., and Chen, J. P. 2017. Jasmonic acidmediated defense suppresses brassinosteroid-mediated susceptibility to rice black streaked dwarf virus infection in rice. New Phytol. 214:388-399.

Hondo, D., Shu, H., Kanayama, Y., Yoshikawa, N., Takenaka, S. and Takahashi, H. 2007. The LeATL6-associated ubiquitin/proteasome system may contribute to fungal elicitor-activated defense response via the jasmonic acid-dependent signaling pathway in tomato. Mol. Plant-Microbe Interact. 20:72-81.

Hossain, M. A., Nakano, Y., and Asada, K. 1984. Monodehydroascorbate reductase in spinach chloroplasts and its participation in regeneration of ascorbate for scavenging hydrogen peroxide. Plant Cell Physiol. 25: 385-395.

Ishii, T., Numaguchi, K., Miura, K., Yoshida, K., Thanh, P. T., Htun, T. M., Yamasaki, M., Komeda, N., Matsumoto, T., Terauchi, R., Ishikawa, R., and Ashikari, M. 2013. OsLG1 regulates a closed panicle trait in domesticated rice. Nat. Genet. 45:462-465.

Islam, W., Qasim, M., Noman, A., Adnan, M., Tayyab, M., Farooq, T. H., Wei, H., and Wang, L. 2018. Plant microRNAs: Front line players against invading pathogens. Microb. Pathog. 118:9-17.

Jabs, T., Dietrich, R. A., and Dangl, J. L. 1996. Initiation of runaway cell death in an Arabidopsis mutant by extracellular superoxide. Science 273: 1853-1856.

Jia, X. L., Chen, Y. K., Xu, X. Z., Zheng, Q. B., Du, Z., Wang, Y., Wu, T., Xu, X. F., Han, Z. H., and Zhang, X. Z. 2017. Mir156 switches on vegetative phase change under the regulation of redox signals in apple seedlings. Sci. Rep. 7: Article 14223.

Jiao, Y. Q., Wang, Y. H., Xue, D. W., Jing, W., Yan, M. X., Liu, G. F., Zeng, D. L., Lu, Z. F., Zhu, X. D., Qian, Q., and Li, J. Y. 2010. Regulation of OsSPL14 by OsmiR156 defines ideal plant architecture in rice. Nat. Genet. 42:541-544.

Karpiński, S., Szechyńskahebda, M., Wituszyńska, W., and Burdiak, P. 2013. Light acclimation, retrograde signalling, cell death and immune defences in plants. Plant Cell Environ. 36:736-744.

Katagiri, F., Thilmony, R., and He, S. Y. 2002. The Arabidopsis thalianapseudomonas syringae interaction. Arabidopsis Book 1:e0039.

Katiyar-Agarwal, S., and Jin, H. 2010. Role of small RNAs in host-microbe interactions. Annu. Rev. Phytopathol. 48:225-246.

Kim, B., Fujioka, S., Kwon, M., Jeon, J., and Choe, S. 2013. Arabidopsis brassinosteroid-overproducing gulliver3-D/dwarf4-D mutants exhibit altered responses to jasmonic acid and pathogen. Plant Cell Rep. 32:1139-1149.

Klessig, D. F., and Malamy, J. 1994. The salicylic acid signal in plants. Pages 203-222 in: Signals and Signal Transduction Pathways in Plants. K. Palme, ed. Springer, Dordrecht, The Netherlands.

Kus, J. V., Zaton, K., Sarkar, R., and Cameron, R. K. 2002. Age-related resistance in Arabidopsis is a developmentally regulated defense response to Pseudomonas syringae. Plant Cell 14:479-490.

Leng, X. P., Wang, P. P., Zhu, X. D., Li, X. P., Zheng, T., Shangguan, L. F., and Fang, J. G. 2017. Ectopic expression of CSD1 and CSD2 targeting genes of miR398 in grapevine is associated with oxidative stress tolerance. Funct. Integr. Genomics 17:697-710.

Li, F., Pignatta, D., Bendix, C., Brunkard, J. O., Cohn, M. M., Tung, J., Sun, H. Y., Kumar, P., and Baker, B. 2012. MicroRNA regulation of plant innate immune receptors. Proc. Natl. Acad. Sci. USA 109:1790-1795.

Li, Y., Lu, Y. G., Shi, Y., Wu, L., Xu, Y. J., Huang, F., Guo, X. Y., Zhang, Y., Fan, J., Zhao, J. Q., Zhang, H. Y., Xu, P. Z., Zhou, J. M., Wu, X. J., Wang, P. R., and Wang, W. M. 2013. Multiple rice microRNAs are involved in immunity against the blast fungus Magnaporthe oryzae. Plant Physiol. 164: 1077-1092.

Livak, K. J., and Schmittgen, T. D. 2001. Analysis of relative gene expression data using real-time quantitative PCR and the $2^{-\Delta \Delta \mathrm{Ct}}$ Method. Methods 25: 402-408.
Lu, S. F., Sun, Y. H., Amerson, H., and Chiang, V. 2007. MicroRNAs in loblolly pine (Pinus taeda L.) and their association with fusiform rust gall development. Plant J. 51:1077-1098.

Lu, Y. Z., Feng, Z., Bian, L. Y., Xie, H., and Liang, J. S. 2011. miR398 regulation in rice of the responses to abiotic and biotic stresses depends on CSD1 and CSD2 expression. Funct. Plant Biol. 38:44-53.

Manning, K., Tör, M., Poole, M., Hong, Y., Thompson, A. J., King, G. J., Giovannoni, J. J., and Seymour, G. B. 2006. A naturally occurring epigenetic mutation in a gene encoding an SBP-box transcription factor inhibits tomato fruit ripening. Nat. Genet. 38:948-952.

Mao, Y. B., Liu, Y. Q., Chen, D. Y., Chen, F. Y., Fang, X., Hong, G. J., Wang, L. J., Wang, J. W., and Chen, X. Y. 2017. Jasmonate response decay and defense metabolite accumulation contributes to age-regulated dynamics of plant insect resistance. Nat. Commun. 8: Article 13925.

Miller, E. W., Dickinson, B. C., and Chang, C. J. 2010. Aquaporin-3 mediates hydrogen peroxide uptake to regulate downstream intracellular signaling. Proc. Natl. Acad. Sci. USA 107:15681-15686.

Miura, K., Ikeda, M., Matsubara, A., Song, X. J., Ito, M., and Asano, K. 2010. OsSPL14 promotes panicle branching and higher grain productivity in rice. Nat. Genet. 42:545-549

Nakano, Y., and Asada, K. 1981. Hydrogen peroxide is scavenged by ascorbate-specific peroxidase in spinach chloroplasts. Plant Cell Physiol. 22:867-880.

Navarro, L., and Jones, J. D. G. 2006. A plant miRNA contributes to antibacterial resistance by repressing auxin signaling. Science 312:436-439.

Nozawa, M., Miura, S., and Nei, M. 2012. Origins and evolution of microRNA genes in plant species. Genome Biol. Evol. 4:230-239.

Padmanabhan, M. S., Ma, S., Burch-Smith, T. M., Czymmek, K., Huijser, P., and Dinesh-Kumar, S. P. 2013. Novel positive regulatory role for the SPL6 transcription factor in the N TIR-NB-LRR receptor-mediated plant innate immunity. PLoS Pathog. 9:e1003235.

Patra, H. K., Kar, M., and Mishra, D. 1978. Catalase activity in leaves and cotyledons during plant development and senescence. Biochem. Physiol. Pflanz. 172:385-390.

Perry, J. J. P., Shin, D. S., Getzoff, E. D., and Tainer, J. A. 2010. The structural biochemistry of the superoxide dismutases. Biochim. Biophys. Acta Proteins Proteomics 1804:245-262.

Petersen, M., Brodersen, P., Naested, H., Andreasson, E., Lindhart, U., Johansen, B., Nielsen, H. B., Lacy, M., Austin, M. J., Parker, J. E., Sharma, S. B., Klessig, D. F., Martienssen, R., Mattsson, O., Jensen, A. B., and Mundy, J. 2000. Arabidopsis MAP kinase 4 negatively regulates systemic acquired resistance. Cell 103:1111-1120.

Pignocchi, C., Kiddle, G., Hernández, I., Foster, S. J., Asensi, A., Taybi, T., Barnes, J., and Foyer, C. H. 2006. Ascorbate oxidase-dependent changes in the redox state of the apoplast modulate gene transcript accumulation leading to modified hormone signaling and orchestration of defense processes in tobacco. Plant Physiol. 141:423-435.

Price, P. W. 1991. The plant vigor hypothesis and herbivore attack. Oikos 62: 244-251.

Rogers, E. E., and Ausubel, F. M. 1997. Arabidopsis enhanced disease susceptibility mutants exhibit enhanced susceptibility to several bacterial pathogens and alterations in $P R-1$ gene expression. Plant Cell 9: 305-316.

Rojas, C. M., Senthil-Kumar, M., Wang, K., Ryu, C. M., Kaundal, A. and Mysore, K. S. 2012. Glycolate oxidase modulates reactive oxygen speciesmediated signal transduction during nonhost resistance in Nicotiana benthamiana and Arabidopsis. Plant Cell 24:336-352.

Schwarz, S., Grande, A. V., Bujdoso, N., Saedler, H., and Huijser, P. 2008. The microRNA regulated SBP-box genes SPL9 and SPL15 control shoot maturation in Arabidopsis. Plant Mol. Biol. 67:183-195.

Slaymaker, D. H., Navarre, D. A., Clark, D., Del, P. O., Martin, G. B., and Klessig, D. F. 2002. The tobacco salicylic acid-binding protein 3 (SABP3) is the chloroplast carbonic anhydrase, which exhibits antioxidant activity and plays a role in the hypersensitive defense response. Proc. Natl. Acad. Sci. USA 99:11640-11645.

Spoel, S. H., Johnson, J. S., and Dong, X. 2007. Regulation of tradeoffs between plant defenses against pathogens with different lifestyles. Proc. Natl. Acad. Sci. USA 104:18842-18847.

Spoel, S. H., Koornneef, A., Claessens, S. M. C., Korzelius, J. P., Van Pelt, J. A., Mueller, M. J., Buchala, A. J., Métraux, J. P., Brown, R., Kazan, K., Van Loon, L. C., Dong, X., and Pieterse, C. M. 2003. NPR1 modulates cross-talk between salicylate- and jasmonate-dependent defense pathways through a novel function in the cytosol. Plant Cell 15:760770 .

Stewart, R. R. C., and Bewley, J. D. 1980. Lipid peroxidation associated with accelerated aging of soybean axes. Plant Physiol. 65:245-248.

Stief, A., Altmann, S., Hoffmann, K., Pant, B. D., Scheible, W. R., and Bäurle, I. 2014. Arabidopsis miR156 regulates tolerance to recurring environmental stress through $S P L$ transcription factors. Plant Cell 26:1792-1807. 
Stone, J. M., Liang, X., Nekl, E. R., and Stiers, J. J. 2005. Arabidopsis AtSPL14, a plant-specific SBP-domain transcription factor, participates in plant development and sensitivity to fumonisin B1. Plant J. 41:744-754.

Telfer, A., Bollman, K. M., and Poethig, R. S. 1997. Phase change and the regulation of trichome distribution in Arabidopsis thaliana. Development 124:645-654.

Torres, M. A, Dangl, J. L., and Jones, J. D. G. 2002. Arabidopsis gp91phox homologues atrbohd and atrbohf are required for accumulation of reactive oxygen intermediates in the plant defense response. Proc. Natl. Acad. Sci. 99:517-522.

Vernooij, B. D., Friedrich, L., Weymann, K., Negrotto, D., Gaffney, T., Gut-Rella, M., et al. 1994. A central role of salicylic acid in plant disease resistance. Science 266:1247-1250.

Vidhyasekaran, P. 2015. Plant Hormone Signaling Systems in Plant Innate Immunity. Signaling and Communication in Plants series. Springer, Dordrecht, The Netherlands.

Wang, H., and Wang, H. Y. 2015. The miR156/SPL module, a regulatory hub and versatile toolbox, gears up crops for enhanced agronomic traits. Mol. Plant 8:677-688.

Wang, J. E., Liu, K. K., Li, D. W., Zhang, Y. L., Zhao, Q., He, Y. M., and Gong, Z. H. 2013. A novel peroxidase canpod gene of pepper is involved in defense responses to Phytophthora capsici infection as well as abiotic stress tolerance. Int. J. Mol. Sci. 14:3158-3177.

Wang, J.-W. 2016. The multifaceted roles of mir156-targeted SPL transcription factors in plant developmental transitions. Pages 281-293 in: Plant Transcription Factors. Elsevier, Inc.

Wang, J.-W., Czech, B., and Weigel, D. 2009. miR156-Regulated SPL transcription factors define an endogenous flowering pathway in Arabidopsis thaliana. Cell 138:738-749.

Wang, J.-W., and Weigel, D. 2008. Dual effects of miR156-targeted SPL genes and $C Y P 78 A 5 / K L U H$ on plastochron length and organ size in Arabidopsis thaliana. Plant Cell 20:1231-1243.

Wang, S., Cui, W. J., Wu, X. Y., Yuan, Q., Zhao, J. P., Zhen, H. Y., Lu, Y. W., Peng, J. J., Lin, L., Chen, J. P., and Yan, F. 2018. Suppression of nbemiR166h-p5 attenuates leaf yellowing symptoms of Potato virus $\mathrm{X}$ on $\mathrm{Ni}$ cotiana benthamiana and reduces virus accumulation. Mol. Plant Pathol. 19:2384-2396

Wang, S. K., Wu, K., Yuan, Q. B., Liu, X., Liu, Z. B., Lin, X. Y., Zeng, R. Z., Zhu, H. T., Dong, G. J., Qian, Q., Zhang, G. Q., and Fu, X. D. 2012. Control of grain size, shape and quality by OsSPL16 in rice. Nat. Genet. 44: 950-954.

Wang, Y., Wang, Z., Amyot, L., Tian, L., Xu, Z., Gruber, M. Y., and Hannoufa, A. 2015. Ectopic expression of miR156 represses nodulation and causes morphological and developmental changes in Lotus japonicus. Mol. Genet. Genomics 290:471-484.
Whalen, M. C., Innes, R. W., Bent, A. F., and Staskawicz, B. J. 1991. Identification of Pseudomonas syringae pathogens of Arabidopsis and a bacterial locus determining avirulence on both Arabidopsis and soybean. Plant Cell 3:49-59.

Wu, G., Park, M. Y., Conway, S. R., Wang, J. W., Weigel, D., and Poethig, R. S. 2009. The sequential action of mir156 and mir172 regulates developmental timing in Arabidopsis. Cell 138:625-627.

Wu, G., and Poetig, R. S. 2006. Temporal regulation of shoot development in Arabidopsis thaliana by mir156 and its target SPL3. Development 133: 3539-3547.

Wu, G., Shortt, B. J., Lawrence, E. B., Levine, E. B., Fitzsimmons, K. C., and Shah, D. M. 1995. Disease resistance conferred by expression of a gene encoding $\mathrm{H}_{2} \mathrm{O}_{2}$-generating glucose oxidase in transgenic potato plants. Plant Cell 7:1357-1368.

Wu, J. G., Yang, R. X., Yang, Z. R., Yao, S. Z., Zhao, S. S., Wang, Y., Li, P. C., Song, X. W., Jin, L., Zhou, T., Lan, Y., Xie, L. H., Zhou, X. P., Chu, C. C., Qi, Y. J., Cao, X. F., and Li, Y. 2017. ROS accumulation and antiviral defence control by microRNA528 in rice. Nat. Plants 3:16203-16209.

Wu, Y., Zhang, D., Chu, J. Y., Boyle, P., Wang, Y., Brindle, I. D., De Luca, V., and Després, C. 2012. The Arabidopsis NPR1 protein is a receptor for the plant defense hormone salicylic acid. Cell Rep. 1:639-647.

Xie, K., Wu, C., and Xiong, L., 2006. Genomic organization, differential expression, and interaction of SQUAMOSA promoter-binding-like transcription factors and microRNA156 in rice. Plant Physiol. 142:280-293.

Yamasaki, H., Abdel-Ghany, S. E., Cohu, C. M., Kobayashi, Y., Shikanai, T., and Pilon, M. 2007. Regulation of copper homeostasis by microRNA in Arabidopsis. J. Biol. Chem. 282:16369-16378.

Yamasaki, H., Hayashi, M., Fukazawa, M., Kobayashi, Y., and Shikanai, T. 2009. SQUAMOSA promoter binding protein-like7 is a central regulator for Copper homeostasis in Arabidopsis. Plant Cell 21:347-361.

Yang, Y. T., Zhang, X., Su, Y. C., Zou, J. K., Wang, Z. T., Xu, L. P., and Que, Y. X. 2017. miRNA alteration is an important mechanism in sugarcane response to low-temperature environment. BMC Genomics 18:833-850.

Yu, Z. X., Wang, L. J., Zhao, B., Shan, C. M., Zhang, Y. H., Chen, D. F., and Chen, X. Y. 2015. Progressive regulation of sesquiterpene biosynthesis in Arabidopsis and patchouli (Pogostemon cablin) by the miR156-targeted $S P L$ transcription factors. Mol. Plant 8:98-110.

Zhang, C., Ding, Z. M., Wu, K. C., Yang, L., Li, Y., Yang, Z., Shi, S., Liu, X. J., Zhao, S. S., Yang, Z. R., Wang, Y., Zheng, L. P., Wei, J., Du, Z. G., Zhang, A. H., Miao, H. Q., Li, Y., Wu, Z. J., and Wu, J. G. 2016. Suppression of jasmonic acid-mediated defense by viral inducible MicroRNA319 facilitates virus infection in rice. Mol. Plant 9:1302-1314.

Zhang, W. X., Gao, S., Zhou, X., Chellappan, P., Chen, Z., Zhou, X. F., Zhang, X. M., Fromuth, N., Coutino, G., Coffey, M., and Jin, H. L. 2011. Bacteriaresponsive microRNAs regulate plant innate immunity by modulating plant hormone networks. Plant Mol. Biol. 75:93-105. 